\title{
Caracterização florística e estrutural de remanescentes florestais de Quedas do Iguaçu, Sudoeste do Paraná
}

\author{
Ricardo Augusto Gorne Viani, ${ }^{1,6}$,Julio César Costa ${ }^{2}$, Adriana de Fátima Rozza ${ }^{3}$, \\ Luis Vicente Brandolise Bufo ${ }^{4}$, Marcelo Antonio Pinho Ferreira ${ }^{1}$ \& Ana Cláudia Pereira de Oliveira ${ }^{5}$
}

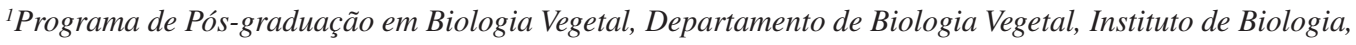
Universidade Estadual de Campinas - UNICAMP, CP 6109, CEP13083-970, Campinas, SP, Brasil

${ }^{2}$ Programa de Pós-graduação em Recursos Florestais, Departamento de Ciências Florestais, Escola Superior de Agricultura Luiz de Queiroz, Universidade de São Paulo - USP, CP 09, CEP 13418-900, Piracicaba, SP, Brasil

${ }^{3}$ Engenheira de Meio Ambiente da Petrobrás - Refinaria Presidente Bernardes Cubatão, Pça. Marechal Stenio Caio de Albuquerque Lima, n. 1, CEP 11555-900, Cubatão, SP, Brasil

${ }^{4}$ Programa de Pós-graduação em Ecologia Aplicada, Universidade de São Paulo - USP, CP 09, CEP 13418-900, Piracicaba, SP, Brasil

${ }^{5}$ Programa de Pós-graduação em Desenvolvimento e Meio Ambiente, Universidade Federal do Rio Grande do Norte - UFRN, Campus Universitário, CEP 59072-970, Natal, RN, Brasil, www.ufrn.br/ufrn/

${ }^{6}$ Autor para correspondência: Ricardo Augusto Gorne Viani, e-mail: ragviani@yahoo.com.br

VIANI, R.A.G., COSTA, J.C., ROZZA, A.F., BUFO, L.V.B., FERREIRA, M.A.P. \& OLIVEIRA, A.C.P. Floristic and structural characterization of forest remnants in Quedas do Iguaçu, Southeastern Paraná. Biota Neotrop. 11(1): http://www.biotaneotropica.org.br/v11n1/en/abstract?article+bn01911012011.

\begin{abstract}
The Southwestern region of Paraná State is an area of great ecological relevance because it represents an ecotone between two important forest types of the Brazilian south-southeastern region: the Seasonal Semideciduous Forest (SSF) and the Araucaria Forest (AF). Despite its importance, there is a lack of floristic surveys and vegetation studies in this region. In this study, we assessed floristic and structural attributes of the vegetation at three different native forest sites, located in Quedas do Iguaçu, Paraná State. Moreover, we made a phytogeografical characterization of the studied forests, based on the data we collected, and on the list of species surveyed in other 52 studies in SSF and AF of Brazil. Samples were taken using the point-centered-quarter method. All individuals with diameter at breast height $\geq 5 \mathrm{~cm}$ were identified to the species level. Together, 128 species were found. Within sites, the number of species varied from 63 to 78. The three areas are distinguished with respect to structure and most abundant species. In addition, the areas differed with respect to the degree of influence of SSF and AF on their floristic composition. Comparatively, the lower altitude area, located in Iguaçu River's valley, has more elements of SSF on its floristic composition, while the other two areas, located in higher altitude areas, are more influenced by AF, with Araucaria angustifolia (Bertol.) Kuntze on their list of species.
\end{abstract}

Keywords: Seasonally Dry Forest, Araucaria Forest, flora, phytogeography, Atlantic Forest.

VIANI, R.A.G., COSTA, J.C., ROZZA, A.F., BUFO, L.V.B., FERREIRA, M.A.P. \& OLIVEIRA, A.C.P. Caracterização florística e estrutural de remanescentes florestais de Quedas do Iguaçu, Sudoeste do Paraná. Biota Neotrop. 11(1): http://www.biotaneotropica.org.br/v11n1/pt/abstract?article+bn01911012011.

Resumo: O sudoeste paranaense localiza-se na transição entre a Floresta Estacional Semidecidual (FES) e a Floresta Ombrófila Mista (FOM), numa região de grande relevância ecológica, por conter duas importantes formações florestais do sul-sudeste brasileiro. Entretanto, essa mesma região é marcada pela escassez de levantamentos florísticos e de caracterização da vegetação. Nesse trabalho é feita a caracterização florística e estrutural de três áreas de vegetação nativa, localizadas em Quedas do Iguaçu, sudoeste do Paraná, na bacia do rio Iguaçu. Além disso, foi feita a caracterização fitogeográfica das florestas estudadas, com base nos dados coletados e na listagem de espécies amostradas em outras 52 áreas de FES ou FOM do Brasil. Em cada uma das três áreas estudadas, a vegetação arbustivo-arbórea (diâmetro à altura do peito $\geq 5 \mathrm{~cm}$ ) foi caracterizada por meio da alocação de pontos quadrantes. No total foram encontradas 128 espécies, com variação entre 63 a 78 para cada área. Cada área apresentou distinção quanto à estrutura e às espécies mais abundantes. Além disso, as áreas se distinguem quanto ao grau de influência da FES e da FOM em sua composição florística. Comparativamente, a área de menor altitude, localizada no vale do Rio Iguaçu, apresenta mais elementos de FES em sua composição florística, enquanto as outras duas áreas, localizadas em trechos mais elevados, têm maior influência da FOM, contando inclusive com a ocorrência de Araucaria angustifolia (Bertol.) Kuntze.

Palavras-chaves: Floresta Estacional, Mata de Araucária, flora, fitogeografia, Mata Atlântica. 


\section{Introdução}

A Mata Atlântica ocupava originalmente cerca de 1,5 milhões de $\mathrm{km}^{2}$ e aproximadamente $13 \%$ do território nacional, sendo o terceiro maior bioma do país em área ocupada (IBGE 2004). Em virtude de seu elevado grau de endemismo (ver Stehmann et al. 2009), da alta diversidade biológica que abriga, da alta taxa de desmatamento já ocorrida, sendo que restam cerca de 11 a $16 \%$ do bioma (Ribeiro et al. 2009), e do alto grau de ameaça por degradação antropogênica a que está submetida, a Mata Atlântica faz parte dos 25 hotspots mundiais, considerados prioritários para a conservação da biodiversidade global (Myers et al. 2000).

Dentre as subformações da Mata Atlântica, destacam-se nas áreas interioranas das regiões sul e sudeste, a Floresta Estacional Semidecidual (FES) e a Floresta Ombrófila Mista (FOM). A FES, como subformação da Mata Atlântica, distribui-se numa faixa de ampla latitude, sendo encontrada em porções do Paraguai e da Argentina e em todas as regiões do país, com exceção da região Norte. A ocorrência desta formação vegetacional esta condicionada a uma dupla estacionalidade climática, com uma estação mais seca ou fria no inverno, quando $20-50 \%$ das árvores do dossel perdem as folhas (Veloso 1992). A FOM ou Mata de Araucária ocorre em áreas frias e altas do Planalto Meridional da região sul e da província de Missiones na Argentina, com pequenas disjunções florísticas situadas nas serras do Mar e da Mantiqueira, na região sudeste do Brasil. Dentre outros aspectos, a FOM caracteriza-se pela presença da Araucaria angustifolia e de espécies de Drymis e Podocarpus (Veloso 1992). Embora a FES e a FOM sejam, em zona extralitorânea, as duas formações florestais mais representativas da região sul-sudeste do Brasil, ambas estão severamente ameaçadas, pois as condições de relevo e solo favoráveis à expansão da agricultura conduziram a taxas elevadas de conversão de florestas em áreas agrícolas (Dinerstein et al. 1995, Di Bitetti et al. 2003).

A Mata Atlântica cobria originalmente $98 \%$ da área do estado do Paraná. No entanto, em 2008 esse valor já havia sido reduzido para menos de $11 \%$ (Fundação SOS Mata Atlântica \& Instituto Nacional de Pesquisas Espaciais 2009), representado principalmente pelo maciço de vegetação nativa ainda existente na Costa Atlântica do extremo leste. Nas porções norte e oeste do interior do estado, a Mata Atlântica é representada principalmente pela FES (Maack 1981, Fundação de Pesquisas Florestais do Paraná 2001), na qual se destacam, pela abundância e/ou dominância, Aspidosperma polyneuron, Gallesia integrifolia, Sorocea bonplandii e membros das famílias Fabaceae, Meliaceae e Moraceae (Dias et al. 2002). Já na porção centro-sul do estado do Paraná, a FOM é a fitoformação predominante, havendo, portanto, a ocorrência de Araucaria angustifolia e de muitas espécies das famílias Lauraceae e Myrtaceae (Dias et al. 2002, Kozera et al. 2006).

Ainda no estado do Paraná, a FES e a FOM constituem uma região de transição (ecótono), dentro da qual existe uma gradação da composição florística e da estrutura da floresta, supostamente condicionada pelo clima e, consequentemente, influenciada pela latitude e altitude (Fundação de Pesquisas Florestais do Paraná 2001). Assim como as áreas de FES e FOM, essas regiões de transição também foram afetadas pela expansão agrícola e encontram-se severamente ameaçadas pelo pequeno tamanho e acentuado nível de isolamento dos fragmentos florestais remanescentes, pela escassez de áreas protegidas e pela forte pressão antropogênica, ainda incidente sobre as florestas existentes (Conservation International do Brasil et al. 2000, Fundação de Pesquisas Florestais do Paraná 2001).

A porção mais baixa do rio Iguaçu, no sudoeste paranaense, corresponde a uma dessas regiões de contato entre a FES e a FOM. Mesmo abrangendo o Parque Nacional do Iguaçu, um dos primeiros a serem criados e uma das Unidades de Conservação mais conhecidas do Brasil, são escassos trabalhos que abordam a riqueza, a diversidade e a estrutura da vegetação remanescente nessa região. Entretanto, o conhecimento da flora nativa de uma determinada região tem papel fundamental na definição de estratégias de conservação da biodiversidade, além de ser um subsídio importante para a realização de pesquisa em diversas áreas do conhecimento. Nesse sentido, este estudo tem os seguintes objetivos: caracterizar florística e estruturalmente três remanescentes de vegetação nativa localizados numa região de transição entre a FES e a FOM no sudoeste do Paraná; e avaliar, por meio da análise de dados secundários coletados nos domínios da FES e da FOM, as espécies características destas formações e a presença de elementos da FES e da FOM na composição florística dos três remanescentes florestais estudados.

\section{Material e Métodos}

\section{1. Áreas de estudo}

Os levantamentos fitossociológicos foram conduzidos na Fazenda

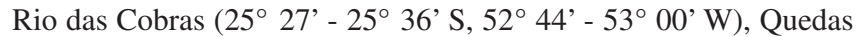
do Iguaçu, sudoeste do Paraná. Dos 24.000 ha da propriedade, aproximadamente 13.000 ha constituem vegetação natural, em diferentes graus de conservação, circundada por cultivos agrícolas anuais e reflorestamentos comerciais de Pinus spp. (Pinaceae) e Araucaria angustifolia (Araucariaceae). Embora fragmentados e com histórico de extração seletiva de madeira, os remanescentes florestais da propriedade contabilizam uma grande área, sendo considerados prioritários para a conservação da biodiversidade na região de domínio da Mata Atlântica (Di Bitetti et al. 2003).

A Fazenda Rio das Cobras localiza-se sobre o Terceiro Planalto Paranaense, subseção do Planalto de Guarapuava, sendo limitada ao sul pelo Rio Iguaçu e a leste pelo Rio das Cobras. A formação geológica local é originada do derrame de Trapp, ocorrido no período Triássico/Cretáceo. Os solos predominantes são o Latossolo Vermelho Férrico, nas áreas mais planas e o Nitossolo Vermelho Férrico associado à Neossolos Litólicos, nas porções mais declivosas e elevadas (Maack 1981, Fundação de Pesquisas Florestais do Paraná 2001). De acordo com a classificação de Koeppen, o clima é do tipo $C f a$, ou seja, subtropical sem estação seca definida, com verões que variam de amenos a quentes (temperatura média do mês mais quente acima dos $22^{\circ} \mathrm{C}$ ) e com baixa frequência de geadas (Maack 1981). No entanto, em estudo realizado por Consórcio Silviconsult - Juris Ambientis (1995) é feita a ressalva que dados coletados em estação meteorológica situada em Quedas do Iguaçu indicam que o clima local é $C f b$, ou seja, subtropical sem estação seca definida, com verões amenos (temperatura média do mês mais quente abaixo dos $22{ }^{\circ} \mathrm{C}$ ), com ocorrência de geadas no inverno. A altitude média é de $513 \mathrm{~m}$ e o relevo regional é predominantemente ondulado, porém ao aproximar-se do rio Iguaçu, a altitude cai e o relevo torna-se mais acidentado e fortemente ondulado (Fundação de Pesquisas Florestais do Paraná 2001).

Dentro da propriedade foram escolhidas três áreas para a caracterização florística e estrutural da vegetação nativa. A Mata do Palmital ( $25^{\circ} 33^{\prime} \mathrm{S}, 52^{\circ} 58^{\prime} \mathrm{W}$, cerca de $450 \mathrm{~m}$ de altitude), situada em encosta à margem do lago do reservatório da usina hidrelétrica Salto Osório, no rio Iguaçu; a Mata do Polonês ( $25^{\circ} 29^{\prime} \mathrm{S}, 52^{\circ} 53^{\prime} \mathrm{W}$, cerca de $550 \mathrm{~m}$ de altitude), estendendo-se da margem do ribeirão Campo Novo até a encosta dos morros adjacentes; e a Reserva das Antas ( $25^{\circ} 28^{\prime} \mathrm{S}, 52^{\circ} 49^{\prime} \mathrm{W}$, cerca de $550 \mathrm{~m}$ de altitude), localizada próxima a curso d'água e com presença de manchas com maior umidade do solo, em função da influência fluvial sazonal (Figura 1). Estas áreas foram selecionadas para o estudo por representarem diferentes altitudes da paisagem local (porção mais baixa localizada a margem do rio Iguaçu até porções mais elevadas nas encostas de morros) e por aparentemente apresentarem as melhores condições de regeneração e conservação dentre os remanescentes existentes na propriedade. 


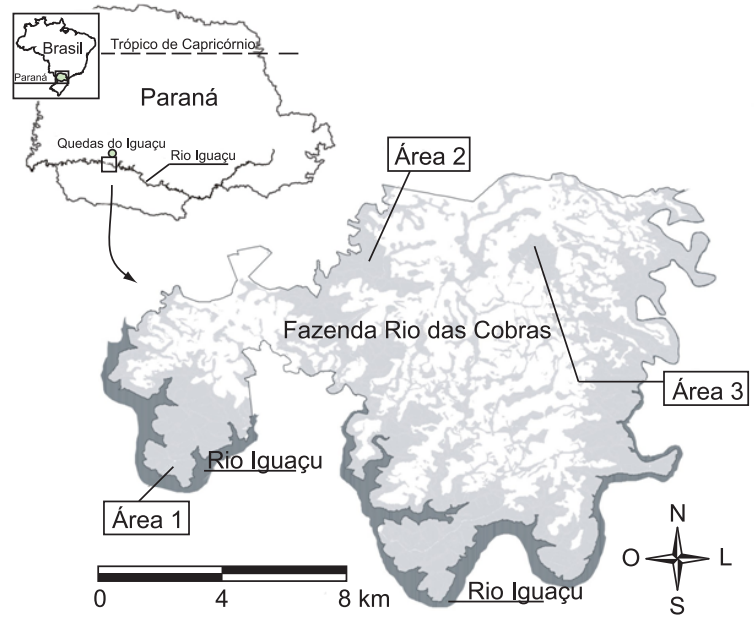

Figura 1. Localização geográfica da Fazenda Rio das Cobras, Quedas do Iguaçu, PR, com indicação das três áreas estudadas, sendo Área 1 a Mata do Palmital; Área 2 a Mata do Polonês; e Área 3 a Reserva das Antas. O cinza claro representa as áreas com vegetação nativa, o cinza escuro o rio Iguaçu e as áreas em branco dentro do mapa correspondem as áreas agrícolas.

Figure 1. Location of "Rio das Cobras" farm, Quedas do Iguaçu, PR, Brazil. Área 1: "Mata do Palmital"; Área 2: "Mata do Polonês"; and Área 3: "Reserva das Antas". The pale grey represents the native forest areas, the dark grey represents the Iguaçu River and the white areas inside the map are the lands used for agriculture.

\section{Método de amostragem}

O levantamento do estrato arbustivo-arbóreo nas três áreas foi feito por meio do método de Quadrantes (Martins 1991). Foram registrados todos os indivíduos com diâmetro à altura do peito (DAP) $\geq 5 \mathrm{~cm}$. Indivíduos ramificados foram incluídos quando a soma da área da seção de cada ramificação à altura do peito $(1,3 \mathrm{~m})$ correspondia a uma seção única com DAP $\geq 5 \mathrm{~cm}$.

Para a alocação dos pontos quadrantes foram utilizadas linhas paralelas, distanciadas aproximadamente $25 \mathrm{~m}$ uma das outras, com pontos de amostragem a cada $15 \mathrm{~m}$. Pontos incidentes sobre áreas dominadas por bambuzais de Guadua tagoara (Nees) Kunth ou Merostachys spp. foram posteriormente descartados. Dessa forma, no total foram alocados 203 (812 indivíduos amostrados), 202 (808) e 195 (780) pontos quadrantes respectivamente na Mata do Palmital, na Mata do Polonês e na Reserva das Antas. A área amostral equivalente, estimada com base nas distâncias entre o centro do quadrante e as árvores amostradas em cada ponto (Martins, 1991), foi de 0,61 ha para a Mata do Palmital, 0,52 ha para a Mata do Polonês e 0,5 ha para a Reserva das Antas.

As plantas foram identificadas por comparação com materiais do acervo do herbário ESA (USP-ESALQ, Piracicaba), por consulta a bibliografia especializada ou com o auxílio de especialistas. As espécies amostradas foram agrupadas em famílias com base nas famílias existentes na APG III (Angiosperm Phylogeny Group 2009) para as angiospermas, em Smith et al. (2006) para pteridófitas e em Souza \& Lorenzi (2008) para gimnospermas.

Foram calculadas a riqueza e o índice de diversidade de Shannon (H') de cada comunidade, sendo posteriormente elaboradas curvas de rarefação com reamostragens aleatórias no programa computacional Ecosim, de modo a permitir a comparação destes parâmetros entre as comunidades. $\mathrm{O}$ número de indivíduos perfilhados e de árvores mortas em pé foi comparado entre comunidades, duas a duas, por meio do teste Qui-quadrado $\left(\chi^{2}\right)$ com correção de Yates $(\mathrm{GL}=1)$ e correção de Bonferroni para correção do valor crítico de $\mathrm{p}$ para comparações múltiplas. Foram obtidas ainda a densidade de indivíduos por hectare e a área basal de cada comunidade avaliada, bem como a densidade relativa das espécies em cada área de estudo. Para facilitar a comparação da flora das três áreas estudadas, foi elaborado diagrama de Venn, destacando o número de espécies exclusivas e comuns entre as áreas. Para verificar a ocorrência de espécies ameaçadas de extinção, comparou-se a lista de espécies obtida nesse levantamento com a lista oficial de espécies da flora ameaçadas de extinção do Brasil (Instrução Normativa $n^{\circ} 6$, de 23/09/2008), e com a lista das espécies vegetais ameaçadas, elaborada pela International Union for Conservation of Nature and Natural Resources (IUCN 2009).

\section{Compilação de dados secundários e caracterização fitogeográfica das áreas estudadas}

Foram compilados os dados de 52 levantamentos fitossociológicos realizados em áreas de ocorrência de FES ou FOM na região sul do Brasil e nos estados de São Paulo e Mato Grosso do Sul. Não foram incluídos nessa compilação estudos referentes a áreas de contato de FES ou FOM com outras formações vegetacionais (por exemplo, Floresta Ombrófila Densa e formações do bioma Cerrado), estudos com critério de inclusão dos indivíduos inferior a $3 \mathrm{~cm}$ de DAP e estudos realizados em áreas de transição entre FES e FOM. Considerando a indicação da formação vegetacional dada pelos autores, do total de levantamentos analisados, 26 são de FES e 26 de FOM (Figura 2, Tabela 1).

Com estes dados secundários foi montada uma matriz de presença e ausência das espécies nas áreas de FES e de FOM. Para a elaboração da matriz foram consideradas apenas as espécies identificadas em nível específico. A listagem de espécies foi conferida com relação à presença de sinonímias por meio da consulta do banco de dados W3 Tropicos, disponível no website do Missouri Botanical Garden (MOBOT 2009) e obras recentes que apresentam sinonímias para as espécies encontradas (ver Oliveira-Filho 2006).

A partir dessa matriz foram obtidas as frequências de cada espécie em FES e FOM. Espécies encontradas em uma única formação (FES ou FOM), em pelo menos cinco trabalhos (9,6\% do total, 19,2\% dos trabalhos de cada formação) foram denominadas típicas da formação de ocorrência. Já espécies que ocorreram nas duas formações, em pelo menos cinco trabalhos em cada $(19,2 \%$ em cada formação e $19,2 \%$ do total) foram consideradas típicas às duas formações. Ressalta-se que, em função dos objetivos propostos neste estudo, estas comparações foram feitas apenas em relação à FES e à FOM, de modo que as espécies denominadas neste estudo como típicas de uma formação podem ter ocorrência em outros biomas e formações não incluídos na análise.

Por fim, para verificar uma maior influência de FES ou FOM na composição das áreas estudadas, foram realizadas comparações, por meio do teste Exato de Fisher com nível de significância de $10 \%$, entre a proporção de espécies típicas de FES e FOM em cada comunidade estudada e a proporção de espécies típicas de FES e FOM encontrada no conjunto de estudos secundários compilados. O teste Exato de Fisher substitui o teste qui-quadrado quando há frequências inferiores a cinco. Dessa forma, a caracterização fitogeográfica dos três remanescentes florestais avaliados em Quedas do Iguaçu - PR, além de considerar os aspectos gerais e estruturais da vegetação, foi feita com base na ocorrência ou não de espécies apontadas como exclusivas da FES ou da FOM pela compilação dos levantamentos secundários selecionados. 


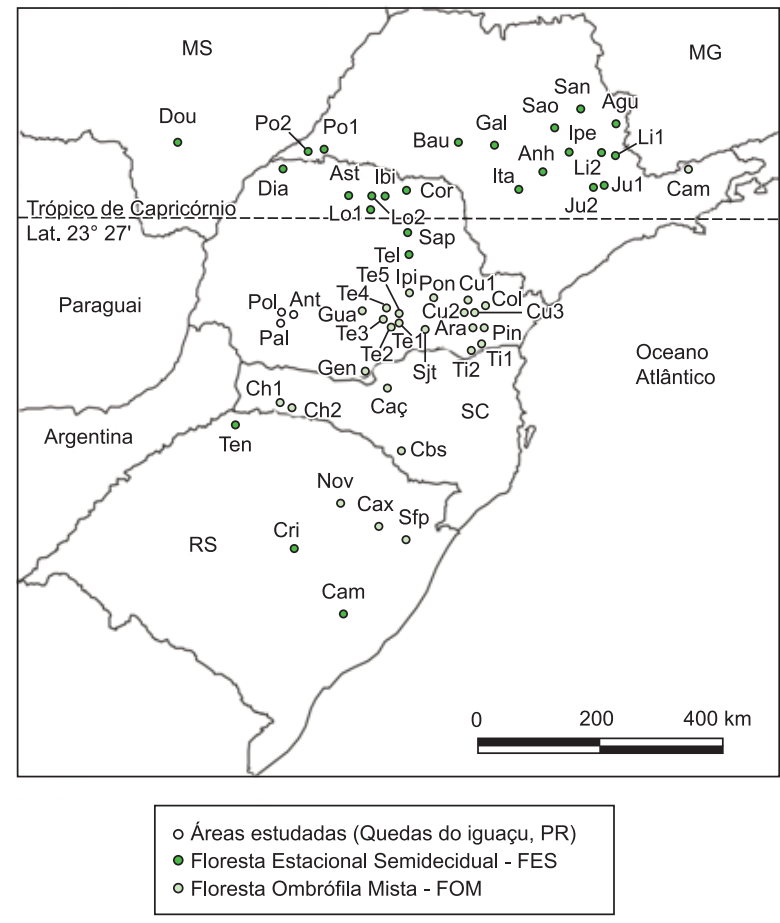

Figura 2. Localização dos levantamentos fitossociológicos realizados em área de FOM e/ou FES, utilizados para comparação florística com as áreas desse estudo. As siglas dos municípios correspondem aos códigos da Tabela 1.

Figure 2. Location of the phytosociological surveys made in Araucaria Forest (FOM) and/or Seasonal Semideciduous Forest (FES) areas used for the floristic comparison with the areas of this study. Codes for municipalities are described in Table 1.

\section{Resultados e Discussão}

\section{Aspectos gerais da vegetação dos remanescentes estudados}

O levantamento fitossociológico nas três áreas da Fazenda Rio das Cobras contabilizou 128 espécies arbustivo-arbóreas, pertencentes a 43 famílias botânicas (Tabela 2). As famílias mais ricas foram Fabaceae (16 espécies), Lauraceae (oito), Myrtaceae (sete) e Solanaceae (sete). Embora não nessa ordem, essas mesmas famílias se destacam como as mais ricas em FES e FOM de outras regiões do estado do Paraná (Dias et al. 2002) e também na Mata Atlântica como um todo (sensu lato) (ver Stehmann et al. 2009). Na Reserva das Antas destacam-se pela riqueza Fabaceae e Lauraceae com sete espécies cada, e na Mata do Polonês, Fabaceae com sete espécies, seguida de Lauraceae e Sapindaceae com cinco espécies cada. Na Mata do Palmital as famílias mais ricas foram Fabaceae (13 espécies), Meliaceae (seis) e Solanaceae (seis), entretanto, quando analisada a densidade de indivíduos, ganha destaque como a mais abundante, a família Arecaceae, com apenas duas espécies, mas com $22 \%$ do total de indivíduos amostrados, corroborando com resultados encontrados nas FES do baixo rio Tibagi, na região Norte do estado do Paraná (Dias et al. 2002).

Do total de espécies, cinco constam em listas de espécies ameaçadas de extinção, sendo que cada área estudada conta com pelo menos duas espécies ameaçadas (Tabela 2). Araucaria angustifolia encontra-se ameaçada tanto na listagem oficial de espécies ameaçadas do Brasil (Instrução Normativa $n^{\circ}$ 6, de 23/09/2008) quanto na listagem elaborada pela IUCN, nesta última na categoria "criticamente em perigo". Euterpe edulis também faz parte da listagem oficial de espécies ameaçadas do Brasil, enquanto Aspidosperma polyneuron, Balfourodendron riedelianum e Cedrela fissilis encontram-se na categoria "em perigo" da listagem elaborada pela IUCN. Vale ressaltar que, exceto Euterpe edulis, espécie de sub-bosque explorada pelo seu palmito comestível, todas as demais espécies ameaçadas encontradas referem-se a árvores de grande porte, frequentemente exploradas como madeireiras. Este aspecto, aliado a fragmentação florestal, causou uma redução significativa de suas populações, o que, por sua vez, representa um risco alto (categoria "em perigo") ou extremamente alto (categoria "criticamente em perigo") para a extinção destas espécies na natureza (IUCN 2009).

Com o esforço amostral empregado para o levantamento, a Mata do Palmital apresentou maior número de espécies que as demais áreas, seguida pela Reserva das Antas e pela Mata do Polonês (Figura 3, Tabela 3). A Mata do Palmital e a Mata do Polonês apresentaram índices de diversidade de Shannon (H') semelhantes (respectivamente 3,33 e 3,31 nats.indiv ${ }^{-1}$ ) e superiores ao da Reserva das Antas (2,68 nats.indiv ${ }^{-1}$ ) (Figura 3). Nessa última, a elevada densidade populacional de Alsophila setosa (Cyatheaceae), que representa $42,4 \%$ do total de indivíduos amostrados, gerou uma baixa equabilidade nos tamanhos das populações e, consequentemente, um menor valor de diversidade. As três áreas apresentaram espécies exclusivas, além de 23 espécies em comum (cerca de $18 \%$ do total de espécies) (Figura 4, Tabela 2). Entretanto, há considerável diferença nas espécies que são mais abundantes em cada área de estudo, de tal forma que apenas Ocotea diospyrifolia, nas três áreas, e Lonchocarpus aff. campestris, no Palmital e na Reserva das Antas, estão entre as 10 espécies de maior densidade relativa em mais de uma área.

Com relação à estrutura da vegetação, a elevada área basal obtida na Mata do Polonês (Tabela 3) é atribuída em parte à presença de um maior número de indivíduos com tronco perfilhado (Tabela 3, com Mata do Palmital $\chi^{2}=74,9$ e $\mathrm{p}<$ 0,001; com Mata do Polonês $\chi^{2}=79,7$ e $\mathrm{p}<0,001 ; p$ crítico com correção de Bonferroni $=0,033$ ), de diversas espécies, como Trichilia elegans, Strychnos brasiliensis, Sebastiania brasiliensis, Matayba elaeagnoides, Diatenopteryx sorbifolia, Calliandra foliolosa, Campomanesia guaviroba, Allophylus edulis e Actinostemon concolor. Um dos fatores prováveis para a presença de grande número de indivíduos perfilhados na Mata do Polonês é o histórico de perturbações antropogênicas, haja vista que a rebrota é uma estratégia de regeneração utilizada pelas plantas após eventos de distúrbio, quando esses não provocam a morte do indivíduo (Kammesheidt 1998, Dickinson et al. 2000, Rodrigues et al. 2004). Em relação ao número de árvores mortas em pé (Tabela 3), não foram encontradas diferenças significativas entre as três florestas estudadas (Mata do Palmital $\times$ Mata do Polonês: $\chi^{2}=2,5$ e $p=0,113$; Mata do Palmital $\times$ Reserva das Antas: $\chi^{2}=3,0 \mathrm{e} \mathrm{p}=0,082$; Mata do Polonês $\times$ Reserva das Antas: $\chi^{2}=2,2$ e $\mathrm{p}=0,134$; $\mathrm{p}$ crítico com correção de Bonferroni $=$ 0,033). Entretanto, as árvores mortas alcançaram destaque nas três comunidades florestais estudadas, estando sempre entre as 10 primeiras em densidade relativa, quando incluídas na análise. Este fato foi constatado também em outros estudos em florestas tropicais do Brasil (e.g. Salis et al. 1994, Dias et al. 1998, Ivanauskas et al. 2002).

Individualmente, as áreas da Fazenda Rio das Cobras não se destacam pela riqueza de espécies. Fatores relacionados ao histórico de perturbações e de corte seletivo de espécies madeireiras nas últimas décadas contribuem para este fato (ver Consórcio Silviconsult-Juris Ambientis 1995). Embora haja limitações para a comparação da riqueza das áreas deste estudo com a de florestas levantadas em outros locais, em função principalmente da heterogeneidade da amostragem, é possível observar que os fragmentos da Fazenda Rio das Cobras, 
Tabela 1. Listagem dos levantamentos florísticos e fitossociológicos da vegetação arbustivo-arbórea, utilizados para a comparação com as áreas desse estudo. CÓD = código da área, utilizado na Figura 2; Lat. = latitude; Long. = longitude; Alt. = altitude; FES = Floresta Estacional Semidecidual; FOM = Floresta Ombrófila Mista; e FES/FOM = região de contato entre as duas formações. O tipo de vegetação foi definido pelos próprios autores do estudo.

Table 1. Floristic and phytosociological surveys (shrub and trees) used to compare with the areas of this study. CÓD = area code (the same in Figure 2); Lat. $=$ latitude Long. $=$ longitude $;$ Alt. $=$ altitude $;$ FES $=$ Seasonal Semideciduous Forest $;$ FOM = Araucaria Forest and FES/FOM $=$ ecotonal zone between the two types of forest. Vegetation type was defined by the authors of each study.

\begin{tabular}{|c|c|c|c|c|c|c|}
\hline CÓD & Localidade/Município & $\begin{array}{l}\text { Lat. } \\
\text { (S) }\end{array}$ & $\begin{array}{l}\text { Long. } \\
\text { (W) }\end{array}$ & $\begin{array}{l}\text { Altitude } \\
(\mathbf{m})\end{array}$ & $\begin{array}{c}\text { Tipo de } \\
\text { Vegetação }\end{array}$ & Fonte \\
\hline PAL & Mata do Palmital & $25^{\circ} 33^{\prime}$ & $52^{\circ} 58^{\prime}$ & 450 & FES/FOM & Esse estudo \\
\hline POL & Mata do Polonês & $25^{\circ} 29^{\prime}$ & $52^{\circ} 53^{\prime}$ & 550 & FES/FOM & Esse estudo \\
\hline ANT & Reserva das Antas & $25^{\circ} 28^{\prime}$ & $52^{\circ} 49^{\prime}$ & 550 & FES/FOM & Esse estudo \\
\hline AGU & Águas da Prata-SP & $21^{\circ} 55^{\prime}$ & $46^{\circ} 42^{\prime}$ & 885 & FES & Toledo Filho et al. (1993) \\
\hline ANH & Anhembi-SP & $22^{\circ} 40^{\prime}$ & $48^{\circ} 10^{\prime}$ & 750 & FES & César \& Leitão-Filho (1990) \\
\hline AST & Astorga-PR & $23^{\circ} 10^{\prime}$ & $51^{\circ} 40^{\prime}$ & 634 & FES & Veiga et al. (2003) \\
\hline BAU & Bauru-SP & $22^{\circ} 19^{\prime}$ & $49^{\circ} 04^{\prime}$ & 570 & FES & Cavassan et al. (1984) \\
\hline CAM & Camaquã-RS & $30^{\circ} 41^{\prime}$ & $51^{\circ} 53^{\prime \prime}$ & 300 & FES & Jurinitz \& Jarenkow (2003) \\
\hline COR & Cornélio Procópio-PR & $23^{\circ} 16^{\prime}$ & $50^{\circ} 45^{\prime}$ & 650 & FES & Tomé et al. (1999) \\
\hline DIA & Diamante do Norte-PR & $22^{\circ} 41^{\prime}$ & $52^{\circ} 55^{\prime}$ & 310 & FES & Costa-Filho et al. (2006) \\
\hline DOU & Dourados-MS & $22^{\circ} 23^{\prime}$ & $54^{\circ} 55^{\prime}$ & 452 & FES & Arruda \& Daniel (2007) \\
\hline GAL & Gália-SP & $22^{\circ} 24^{\prime}$ & $44^{\circ} 42^{\prime}$ & 522 & FES & Durigan et al. (2002) \\
\hline IBI & Ibiporã-PR & $23^{\circ} 16^{\prime}$ & $51^{\circ} 03^{\prime}$ & 484 & FES & Soares-Silva et al. (1992) \\
\hline IPE & Ipeúna-SP & $22^{\circ} 26^{\prime}$ & $47^{\circ} 43^{\prime}$ & 612 & FES & Bertani et al. (2001) \\
\hline ITA & Itatinga-SP & $23^{\circ} 19^{\prime}$ & $48^{\circ} 37^{\prime}$ & 582 & FES & Ivanauskas et al. (2002) \\
\hline JU1 & Jundiaí-SP & $23^{\circ} 11^{\prime}$ & $46^{\circ} 52^{\prime}$ & 870 & FES & Rodrigues et al. (1989) \\
\hline JU2 & Jundiaí-SP & $23^{\circ} 11^{\prime}$ & $46^{\circ} 52^{\prime}$ & 1170 & FES & Rodrigues et al. (1989) \\
\hline LI1 & Lindoia-SP & $22^{\circ} 32^{\prime}$ & $46^{\circ} 58^{\prime}$ & 700 & FES & Toledo Filho et al. (2000) \\
\hline LI2 & Lindoia-SP & $22^{\circ} 32^{\prime}$ & $46^{\circ} 58^{\prime}$ & 900 & FES & Toledo Filho et al. (2000) \\
\hline LO1 & Londrina-PR & $23^{\circ} 27^{\prime}$ & $51^{\circ} 15^{\prime}$ & 585 & FES & Biachini et al. (2003) \\
\hline $\mathrm{LO} 2$ & Londrina-PR & $23^{\circ} 27^{\prime}$ & $51^{\circ} 15^{\prime}$ & 700 & FES & Soares-Silva \& Barroso (1992) \\
\hline SAN & Santa Rita do Passa Quatro & $21^{\circ} 41^{\prime}$ & $47^{\circ} 36^{\prime}$ & 590 & FES & Vieira et al. (1989) \\
\hline $\mathrm{SAO}$ & São Carlos-SP & $21^{\circ} 58^{\prime}$ & $47^{\circ} 50^{\prime}$ & 850 & FES & Silva \& Soares (2002) \\
\hline SAP & Sapopema-PR & $24^{\circ} 01^{\prime}$ & $50^{\circ} 41^{\prime}$ & 780 & FES & Chagas e Silva et al. (1995) \\
\hline TEL & Telêmaco Borba-PR & $24^{\circ} 20^{\prime}$ & $50^{\circ} 37^{\prime}$ & 600 & FES & Nakajima et al. (1996) \\
\hline TEN & Tenente Portela-RS & $27^{\circ} 10^{\prime}$ & $53^{\circ} 55^{\prime}$ & 247 & FES & Vasconcellos et al. (1992) \\
\hline TS1 & Teodoro Sampaio-SP & $22^{\circ} 19^{\prime}$ & $55^{\circ} 20^{\prime}$ & 430 & FES & Durigan et al. (2002) \\
\hline TS2 & Teodoro Sampaio-SP & $22^{\circ} 19^{\prime}$ & $55^{\circ} 20^{\prime}$ & 430 & FES & Durigan et al. (2002) \\
\hline VAL & Vale do Sol-RS & $29^{\circ} 34^{\prime}$ & $52^{\circ} 40^{\prime}$ & 120 & FES & Jarenkow \& Waechter (2001) \\
\hline ARA & Araucária-PR & $25^{\circ} 35^{\prime} 12^{\prime \prime}$ & $49^{\circ} 20^{\prime} 45^{\prime \prime}$ & 900 & FOM & Barddal et al. (2004) \\
\hline $\mathrm{CAÇ}$ & Caçador-SC & $26^{\circ} 47^{\prime}$ & $51^{\circ} 01^{\prime}$ & 1110 & FOM & Negrelle \& Silva (1992) \\
\hline CAM & Campos do Jordão-SP & $22^{\circ} 41^{\prime}$ & $45^{\circ} 28^{\prime}$ & 1467 & FOM & Souza (2008) \\
\hline CBS & Campo Belo do Sul-SC & $28^{\circ} 00^{\prime}$ & $50^{\circ} 49^{\prime}$ & 1017 & FOM & Formento et al. (2004) \\
\hline $\mathrm{CH} 1$ & Chapecó-SC & $27^{\circ} 05^{\prime}$ & $52^{\circ} 37^{\prime}$ & 668 & FOM & Brunetto et al. (2003) \\
\hline $\mathrm{CH} 2$ & Chapecó-SC & $27^{\circ} 05^{\prime}$ & $52^{\circ} 37^{\prime}$ & 668 & FOM & Brunetto et al. (2003) \\
\hline $\mathrm{COL}$ & Colombo-PR & $25^{\circ} 20$ & $49^{\circ} 14^{\prime}$ & 920 & FOM & Oliveira \& Rota (1982) \\
\hline CRI & Criúva-RS & $29^{\circ} 00^{\prime}$ & $50^{\circ} 56^{\prime}$ & 860 & FOM & Rondon Neto et al. (2002) \\
\hline CU1 & Curitiba-PR & $25^{\circ} 26^{\prime}$ & $49^{\circ} 14^{\prime}$ & 900 & FOM & Rondon Neto et al. (2002) \\
\hline CU2 & Curitiba-PR & $25^{\circ} 26^{\prime}$ & $49^{\circ} 14^{\prime}$ & 923 & FOM & Nascimento et al. (2007) \\
\hline CU3 & Curitiba-PR & $25^{\circ} 26^{\prime}$ & $49^{\circ} 14^{\prime}$ & 900 & FOM & Kozera et al. (2006) \\
\hline GEN & General Carneiro-PR & $26^{\circ} 23^{\prime}$ & $51^{\circ} 22^{\prime}$ & 983 & FOM & Wazlawick et al. (2005) \\
\hline GUA & Guarapuava-PR & $25^{\circ} 21^{\prime} 26^{\prime \prime}$ & $51^{\circ} 28^{\prime} 08^{\prime \prime}$ & 1070 & FOM & Cordeiro \& Rodrigues (2007) \\
\hline IPI & Ipiranga-PR & $25^{\circ} 01^{\prime}$ & $50^{\circ} 30^{\prime}$ & 806 & FOM & Silva et al. (1992) \\
\hline NOP & Nova Prata-RS & $28^{\circ} 56^{\prime}$ & $51^{\circ} 53^{\prime}$ & 662 & FOM & Nascimento et al. (2001) \\
\hline PIN & Pinhais-PR & $25^{\circ} 24^{\prime} 25^{\prime \prime}$ & $49^{\circ} 07^{\prime} 50^{\prime \prime}$ & 900 & FOM & Seger et al. (2005) \\
\hline PON & Ponta Grossa-PR & $23^{\circ} 03^{\prime}$ & $50^{\circ} 15^{\prime}$ & 1112 & FOM & Negrelle \& Leuchtenberger (2001) \\
\hline SFP & São Francisco de Paula-RS & $29^{\circ} 02^{\prime}$ & $50^{\circ} 23^{\prime}$ & 922 & FOM & Longhi et al. (2005) \\
\hline SJT & São João do Triunfo-PR & $25^{\circ} 34^{\prime} 18^{\prime \prime}$ & $50^{\circ} 05^{\prime} 56^{\prime \prime}$ & 780 & FOM & Schaaf et al. (2006) \\
\hline TE1 & Teixeira Soares-PR & $25^{\circ} 27^{\prime}$ & $50^{\circ} 35^{\prime}$ & 870 & FOM & Galvão et al. (1989) \\
\hline TE2 & Teixeira Soares-PR & $25^{\circ} 27^{\prime}$ & $50^{\circ} 35^{\prime}$ & 870 & FOM & Galvão et al. (1989) \\
\hline TE3 & Teixeira Soares-PR & $25^{\circ} 27^{\prime}$ & $50^{\circ} 35^{\prime}$ & 870 & FOM & Galvão et al. (1989) \\
\hline TE4 & Teixeira Soares-PR & $25^{\circ} 27^{\prime}$ & $50^{\circ} 35^{\prime}$ & 870 & FOM & Galvão et al. (1989) \\
\hline TE5 & Teixeira Soares-PR & $25^{\circ} 27$ & $50^{\circ} 35^{\prime}$ & 870 & FOM & Galvão et al. (1989) \\
\hline TJ1 & Tijucas do Sul-PR & $24^{\circ} 55^{\prime}$ & $49^{\circ} 12^{\prime}$ & 850 & FOM & Geraldi et al. (2005) \\
\hline $\mathrm{TJ} 2$ & Tijucas do Sul-PR & $24^{\circ} 55^{\prime}$ & $49^{\circ} 12^{\prime}$ & 850 & FOM & Geraldi et al. (2005) \\
\hline
\end{tabular}


Tabela 2. Espécies amostradas na Fazenda Rio das Cobras, Quedas do Iguaçu, PR e suas densidades relativas em cada área de estudo. Ameaça indica o "status" de ameaça da espécie junto à lista de espécies ameaçadas de extinção. O "X" representa que a espécie consta na lista oficial de espécies ameaçadas do Brasil. Para as listadas pela IUCN (2009), CR: em perigo crítico, EN: em perigo. A exclusividade a FES ou a FOM está relacionada a ocorrência em apenas uma dessas formações, em pelo menos cinco áreas dos trabalhos secundários em área de FES ou FOM levantados neste estudo.

Table 2. Species surveyed and their relative density in each of the three areas studied in Rio das Cobras' farm, Quedas do Iguaçu-PR, Brazil. "Ameaça" refers to the status in red lists of threatened species. "X" means that the species is on the Brazilian official red list. For species in the IUCN (2009) red list, CR: critically endangered. EN: endangered Exclusivity to FES or FOM is related to the occurrence in only one of these formations, in at least five FES or FOM secondary surveys compiled for this study.

\begin{tabular}{|c|c|c|c|c|c|c|}
\hline Família & Espécie & Ameaça & Exclusividade & $\begin{array}{c}\text { Reserva } \\
\text { das Antas }\end{array}$ & $\begin{array}{l}\text { Mata do } \\
\text { Palmital }\end{array}$ & $\begin{array}{l}\text { Mata do } \\
\text { Polonês }\end{array}$ \\
\hline Annonaceae & Annona emarginata (Schltdl.) H.Rainer & & FOM & 0,14 & 0,27 & 0,53 \\
\hline Annonaceae & Rollinia sericea (R.E. Fr.) R.E. Fr & & & 0,40 & 0,40 & - \\
\hline Apocynaceae & Aspidosperma polyneuron Müll. Arg. & $\mathrm{EN}$ & FES & - & 0,94 & - \\
\hline Apocynaceae & Rauvolfia sellowii Müll. Arg. & & & 2,82 & - & - \\
\hline Apocynaceae & Tabernaemontana catharinensis A. DC. & & FES & - & 0,13 & - \\
\hline Aquifoliaceae & Ilex brevicuspis Reissek & & & 0,14 & - & 0,53 \\
\hline Aquifoliaceae & Ilex paraguariensis A. St.-Hil. & & & 1,20 & - & - \\
\hline Araliaceae & Schefflera cf. calva (Cham.) Frodin \& Fiaschi & & & - & - & 0,13 \\
\hline Araliaceae & Schefflera morototoni (Aubl.) Maguire, Steyerm. \& Frodin & & & - & 0,13 & - \\
\hline Araucariaceae & Araucaria angustifolia (Bertol.) Kuntze & $\mathrm{X}, \mathrm{CR}$ & FOM & 0,67 & - & 0,40 \\
\hline Arecaceae & Euterpe edulis Mart. & $\mathrm{X}$ & FES & - & 23,82 & - \\
\hline Arecaceae & Syagrus romanzoffiana (Cham.) Glassman & & & - & - & 0,27 \\
\hline Asparagaceae & Cordyline spectabilis Kunth \& Buoché & & & 2,42 & - & 0,66 \\
\hline Asteraceae & Vernonanthura diffusa (Less.) H.Rob & & & - & 0,27 & 15,86 \\
\hline Asteraceae & Vernonanthura petiolaris (DC.) H.Rob & & & 0,14 & - & - \\
\hline Bignoniaceae & Jacaranda puberula Cham. & & & 1,20 & 0,27 & 0,13 \\
\hline Bignoniaceae & Jacaratia spinosa (Aubl.) A. DC. & & FES & 0,14 & 1,08 & - \\
\hline Boraginaceae & Cordia americana $\mathrm{L}$. & & & 0,81 & 0,27 & 0,53 \\
\hline Boraginaceae & Cordia ecalyculata Vell. & & FES & - & 2,28 & - \\
\hline Boraginaceae & Cordia trichotoma (Vell.) Arráb. ex Steud. & & & 0,27 & 0,68 & - \\
\hline Cannabaceae & Celtis iguanaea (Jacq.) Sarg. & & & 0,14 & 0,68 & - \\
\hline Cannabaceae & Trema micrantha (L.) Blume & & & 0,40 & - & - \\
\hline Cardiopteridaceae & Citronella paniculata (Mart.) R.A. Howard & & & - & 0,40 & - \\
\hline Celastraceae & Maytenus aquifolia Mart. & & & - & 0,13 & 0,13 \\
\hline Clethraceae & Clethra scabra Pers. & & & 0,14 & - & - \\
\hline Clusiaceae & Garcinia gardneriana (Planch. \& Triana) Zappi & & & - & 0,27 & - \\
\hline Cyatheaceae & Alsophila setosa Kaulf. & & & 44,42 & - & 0,13 \\
\hline Cyatheaceae & Cyathea sp. & & & 0,27 & - & - \\
\hline Erythroxyllaceae & Erythroxyllum sp. & & & - & - & 0,13 \\
\hline Euphorbiaceae & Actinostemon concolor (Spreng.) Müll. Arg. & & & - & 2,28 & 5,95 \\
\hline Euphorbiaceae & Alchornea glandulosa Poepp. & & FES & 0,53 & 1,48 & - \\
\hline Euphorbiaceae & Alchornea triplinervia (Spreng.) Müll. Arg. & & & 0,14 & - & - \\
\hline Euphorbiaceae & Manihot grahamii Hook & & & - & 0,13 & 0,40 \\
\hline Euphorbiaceae & Sebastiania brasiliensis Spreng. & & & - & 0,27 & - \\
\hline Euphorbiaceae & Sebastiania commersoniana (Baill.) L.B. Sm. \& Downs & & & - & 0,13 & 8,46 \\
\hline $\begin{array}{l}\text { Fab.- } \\
\text { Caesalpinoideae }\end{array}$ & Bauhinia forficata Link & & & - & 0,54 & 0,40 \\
\hline $\begin{array}{l}\text { Fab.- } \\
\text { Caesalpinoideae }\end{array}$ & Peltophorum dubium (Spreng.) Taub. & & FES & 0,53 & 0,40 & 0,27 \\
\hline Fab.-Mimosoideae & Calliandra foliolosa Benth. & & & - & - & 2,24 \\
\hline Fab.-Mimosoideae & Enterolobium contortisiliquum (Vell.) Morong & & FES & 1,08 & 0,27 & - \\
\hline Fab.-Mimosoideae & Inga marginata Willd. & & & - & 7,67 & - \\
\hline Fab.-Mimosoideae & Parapiptadenia rigida (Benth.) Brenan & & & 0,94 & 0,40 & 0,93 \\
\hline Fab.-Mimosoideae & Senegalia polyphylla (DC.) Britton \& Rose & & & - & - & 0,27 \\
\hline $\begin{array}{l}\text { Fab.- } \\
\text { Papilionoideae }\end{array}$ & Apuleia leiocarpa (Vogel) J.F. Macbr. & & FES & - & 1,62 & - \\
\hline $\begin{array}{l}\text { Fab.- } \\
\text { Papilionoideae }\end{array}$ & Erythrina falcata Benth. & & & - & 0,40 & - \\
\hline $\begin{array}{l}\text { Fab.- } \\
\text { Papilionoideae }\end{array}$ & Holocalyx balansae Micheli & & FES & 0,14 & 0,13 & - \\
\hline
\end{tabular}


Tabela 2. Continuação...

\begin{tabular}{|c|c|c|c|c|c|c|}
\hline Família & Espécie & Ameaça & Exclusividade & $\begin{array}{c}\text { Reserva } \\
\text { das Antas }\end{array}$ & $\begin{array}{l}\text { Mata do } \\
\text { Palmital }\end{array}$ & $\begin{array}{l}\text { Mata do } \\
\text { Polonês }\end{array}$ \\
\hline $\begin{array}{l}\text { Fab.- } \\
\text { Papilionoideae }\end{array}$ & Lonchocarpus aff. campestris Mart. ex Benth. & & & 0,14 & 2,56 & 3,83 \\
\hline $\begin{array}{l}\text { Fab.- } \\
\text { Papilionoideae }\end{array}$ & Luetzelburgia guaissara Toledo & & & - & 0,40 & 1,06 \\
\hline $\begin{array}{l}\text { Fab.- } \\
\text { Papilionoideae }\end{array}$ & Machaerium hirtum (Vell.) Stellfeld & & & - & 0,13 & - \\
\hline $\begin{array}{l}\text { Fab.- } \\
\text { Papilionoideae }\end{array}$ & Machaerium sp. & & & - & 0,13 & - \\
\hline $\begin{array}{l}\text { Fab.- } \\
\text { Papilionoideae }\end{array}$ & Machaerium stipitatum (DC.) Vogel & & & 0,27 & 1,48 & - \\
\hline $\begin{array}{l}\text { Fab.- } \\
\text { Papilionoideae }\end{array}$ & Myrocarpus frondosus Allemão & & FES & 0,14 & - & - \\
\hline Lamiaceae & Aegiphilla mediterranea Vell. & & & 0,81 & 2,69 & - \\
\hline Lauraceae & Cinnamomum cf. triplinerve (Ruiz \& Pav.) Kosterm. & & & - & - & 0,66 \\
\hline Lauraceae & Nectandra lanceolata Nees & & & 0,40 & - & - \\
\hline Lauraceae & Nectandra megapotamica (Spreng.) Mez & & & 2,28 & 0,13 & 0,93 \\
\hline Lauraceae & Ocotea diospyrifolia (Meisn.) Mez & & & 4,43 & 5,39 & 8,19 \\
\hline Lauraceae & Ocotea indecora (Schott) Mez & & & 2,95 & 1,08 & 0,53 \\
\hline Lauraceae & Ocotea puberula (Rich.) Nees & & & 0,27 & - & - \\
\hline Lauraceae & Ocotea silvestris Vattimo & & FES & 0,53 & - & - \\
\hline Lauraceae & Ocotea sp. & & & 0,53 & 0,40 & 0,40 \\
\hline Loganiaceae & Strychnos brasiliensis (Spreng.) Mart. & & & 0,81 & 6,20 & 0,13 \\
\hline Malvaceae & Bastardiopsis densiflora (Hook. \& Arn.) Hassl. & & & - & 0,81 & - \\
\hline Malvaceae & Ceiba speciosa (A. St.-Hil.) Ravenna & & FES & - & 0,54 & - \\
\hline Malvaceae & Guazuma ulmifolia Lam. & & & 0,14 & - & - \\
\hline Malvaceae & Luehea divaricata Mart. & & & 1,08 & 0,13 & 2,65 \\
\hline Melastomataceae & Miconia hymenonervia (Raddi) Cogn. & & & - & 0,13 & - \\
\hline Meliaceae & Cabralea canjerana (Vell.) Mart. & & & 0,53 & 2,02 & 0,13 \\
\hline Meliaceae & Cedrella fissilis Vell. & EN & & 9,93 & 0,81 & 1,19 \\
\hline Meliaceae & Guarea kunthiana A. Juss. & & & - & 0,94 & - \\
\hline Meliaceae & Guarea macrophylla Vahl & & & - & 0,40 & - \\
\hline Meliaceae & Trichilia claussenii C. DC. & & FES & - & 1,34 & - \\
\hline Meliaceae & Trichilia elegans A. Juss. & & & - & 0,13 & - \\
\hline Monimiaceae & Hennecartia omphalandra Poiss. & & & - & - & 0,13 \\
\hline Monimiaceae & Mollinedia elegans Tul. & & & 0,14 & - & 0,27 \\
\hline Moraceae & Ficus adhatodifolia Schott ex Spreng. & & & 0,14 & 0,94 & - \\
\hline Moraceae & Ficus glabra Vell. & & & - & 0,13 & - \\
\hline Moraceae & Ficus guaranitica Chodat. & & & 0,27 & - & - \\
\hline Moraceae & Ficus sp. & & & 0,14 & - & - \\
\hline Moraceae & Maclura tinctoria (L.) D. Don ex Steud. & & FES & - & 0,27 & - \\
\hline Moraceae & $\begin{array}{l}\text { Sorocea bonplandii (Baill.) W.C. Burger, Lanj. \& Wess. } \\
\text { Boer }\end{array}$ & & & 0,14 & - & 0,13 \\
\hline Myrsinaceae & Myrsine balansae (Mez) Otegui & & & - & - & 0,13 \\
\hline Myrsinaceae & Myrsine coriacea (Sw.) R. Br. ex Roem. \& Schult. & & & 1,20 & 0,68 & 1,72 \\
\hline Myrsinaceae & Myrsine umbellata Mart. & & & 0,81 & - & - \\
\hline Myrtaceae & Campomanesia guaviroba (DC.) Kiaersk. & & FES & 0,14 & 1,88 & 2,65 \\
\hline Myrtaceae & Campomanesia guazumifolia (Cambess.) O. Berg. & & & 0,14 & - & - \\
\hline Myrtaceae & Eugenia blastantha (O. Berg) D. Legrand & & FES & 0,14 & - & - \\
\hline Myrtaceae & Eugenia burkartiana (D. Legrand) D. Legrand & & & - & 1,08 & 0,13 \\
\hline Myrtaceae & Eugenia uniflora L. & & & - & - & 0,40 \\
\hline Myrtaceae & Myrcia retorta Cambess. & & & - & - & - \\
\hline Myrtaceae & Myrcia sp. & & & 0,14 & - & - \\
\hline Phytolacaceae & Seguieria cf. americana L. & & & - & - & 2,35 \\
\hline Polygonaceae & Ruprechtia laxiflora Meisn. & & & - & - & 0,13 \\
\hline Rosaceae & Prunus myrtifolia (L.) Urb. & & & - & 0,94 & 0,13 \\
\hline Rubiaceae & Chomelia obtusa Cham. \& Schltdl. & & & - & - & 0,13 \\
\hline Rubiaceae & Cordiera concolor (Cham.) Kuntze & & & 0,14 & - & - \\
\hline Rubiaceae & Psychotria sp. & & & - & - & 0,13 \\
\hline
\end{tabular}


Tabela 2. Continuação...

\begin{tabular}{|c|c|c|c|c|c|c|}
\hline Família & Espécie & Ameaça & Exclusividade & $\begin{array}{c}\text { Reserva } \\
\text { das Antas }\end{array}$ & $\begin{array}{l}\text { Mata do } \\
\text { Palmital } \\
\end{array}$ & $\begin{array}{c}\text { Mata do } \\
\text { Polonês } \\
\end{array}$ \\
\hline Rubiaceae & Simira corumbensis (Standl.) Steyerm. & & & - & 0,27 & 2,51 \\
\hline Rutaceae & Balfourodendron riedelianum (Engl.) Engl. & EN & FES & - & 0,81 & - \\
\hline Rutaceae & Pilocarpus pennatifolius Lem. & & & - & 0,13 & - \\
\hline Rutaceae & Zanthoxylum fagara (L.) Sarg. & & & 0,14 & - & - \\
\hline Rutaceae & Zanthoxylum rhoifolium Lam. & & & 0,14 & - & 0,13 \\
\hline Rutaceae & Zanthoxylum riedelianum Engl. & & & 0,67 & - & 0,13 \\
\hline Salicaceae & Casearia decandra Jacq. & & & 0,14 & - & 0,13 \\
\hline Salicaceae & Casearia obliqua Spreng. & & & 1,48 & - & 0,40 \\
\hline Salicaceae & Casearia sylvestris $\mathrm{Sw}$. & & & 3,62 & 0,68 & 0,13 \\
\hline Salicaceae & Prockia crucis $\mathrm{P}$. Browne ex L. & & FES & 0,14 & 0,40 & 0,13 \\
\hline Sapindaceae & Allophylus edulis (A. St.-Hil., Cambess. \& A. Juss.) Radlk. & & & 0,53 & 0,27 & 3,83 \\
\hline Sapindaceae & Allophylus guaraniticus (St. Hil.) Radlk. & & & - & - & 0,66 \\
\hline Sapindaceae & Cupania vernalis Cambess. & & & - & 0,13 & 0,93 \\
\hline Sapindaceae & Diatenopteryx sorbifolia Radlk. & & & 1,08 & 0,27 & 5,69 \\
\hline Sapindaceae & Matayba elaeagnoides Radlk. & & & 0,53 & - & 4,62 \\
\hline Sapotaceae & Chrysophyllum gonocarpum (Mart. \& Eichler) Engl. & & FES & 0,53 & 2,28 & 0,66 \\
\hline Sapotaceae & Chrysophyllum marginatum (Hook. \& Arn.) Radlk. & & FES & 0,40 & 0,13 & - \\
\hline Simaroubaceae & Picrasma crenata (Vell.) Engl. in Engl. \& Prantl & & & 0,14 & - & 3,57 \\
\hline Solanaceae & Cestrum intermedium Sendtn. & & & 0,14 & 1,75 & 0,13 \\
\hline Solanaceae & Cestrum sp. & & & - & 0,13 & - \\
\hline Solanaceae & Solanum mauritianum Scop. & & & - & 0,27 & - \\
\hline Solanaceae & Solanum pseudoquina A.St.-Hil. & & & 0,14 & 0,13 & - \\
\hline Solanaceae & Solanum sanctae-catharinae Dunal & & & 0,14 & - & - \\
\hline Solanaceae & Solanum sp. & & & 0,14 & 0,13 & - \\
\hline Solanaceae & Solanum variabile Mart. & & & - & 0,13 & - \\
\hline Styracaceae & Styrax acuminatus Pohl & & & - & 2,83 & 1,06 \\
\hline Styracaceae & Styrax leprosus Hook. \& Arn. & & & 0,14 & - & 0,27 \\
\hline Symplocaceae & Symplocos cf. tetrandra Mart. & & & 0,81 & 0,27 & 0,53 \\
\hline Urticaceae & Cecropia pachystachya Trécul & & & - & 0,27 & - \\
\hline Urticaceae & Urera baccifera (L.) Gaudich. ex Wedd. & & FES & - & 6,73 & - \\
\hline Verbenaceae & Aloysia virgata (Ruiz \& Pav.) Juss. & & FES & - & 0,40 & - \\
\hline Indeterminada & Indet sp1 & & & 1,20 & - & - \\
\hline Indeterminada & Indet sp2 & & & - & - & 6,74 \\
\hline
\end{tabular}
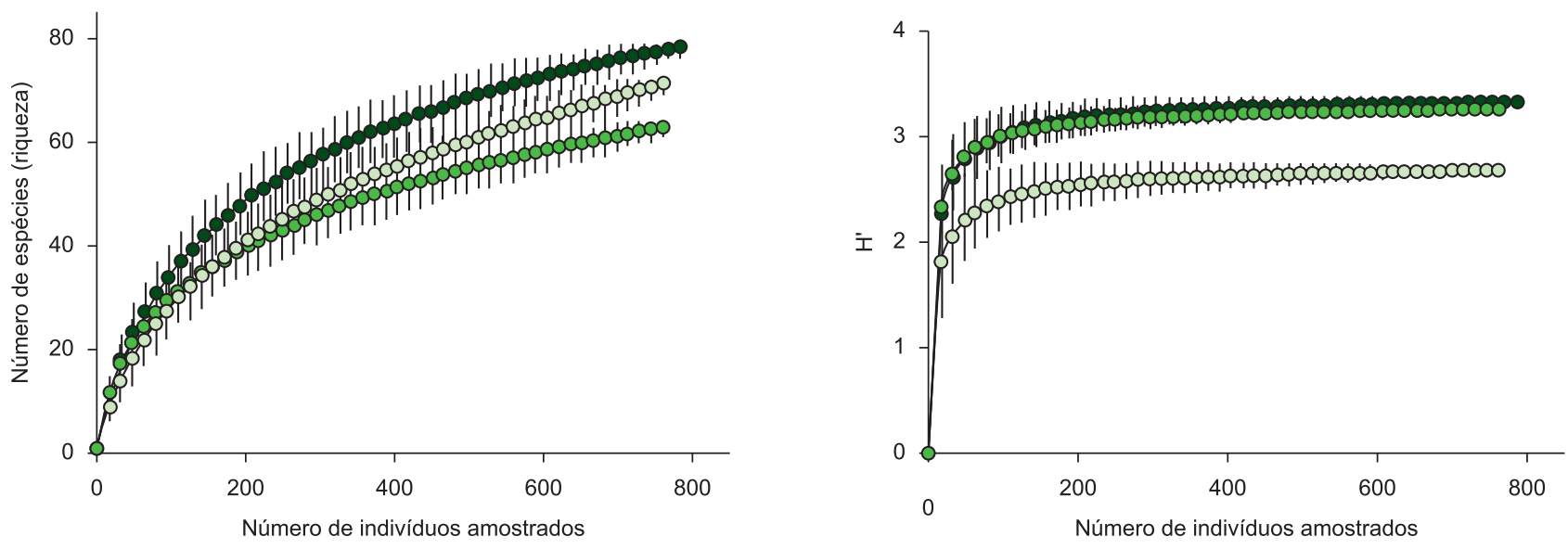

- Mata do Palmital $\quad$ Mata do Polonês $\quad \circ$ Reserva das Antas

Figura 3. Curvas de rarefação da riqueza e da diversidade (H') para as três áreas estudadas em Quedas do Iguaçu-PR. As barras verticais correspondem aos limites inferiores e superiores do intervalo de confiança da média $(\mathrm{p}=0,05)$.

Figure 3. Richness and diversity (H') rarefaction curves for the three surveyed areas. Vertical bars represent upper and lower limits of the confidence interval for the mean $(\mathrm{p}=0.05)$. 
Tabela 3. Principais parâmetros florísticos e estruturais das três comunidades estudadas na Fazenda Rio das Cobras, Quedas do Iguaçu, PR. Os parâmetros descritos são apresentados na seguinte seqüência: número de espécies, número de famílias, de densidade por hectare, área basal, número de plantas com mais de um caule e número de plantas mortas pesquisadas.

Table 3. Main floristic and structural characteristics of the three communities surveyed in "Fazenda Rio das Cobras", Quedas do Iguaçu-PR, Brazil. The parameters described are presented in the following sequence: number of species, number of families, density per hectare, basal area, number of plants with more than one stem and number of dead plants surveyed.

\begin{tabular}{|c|c|c|c|c|c|c|}
\hline Área & $\begin{array}{c}\text { N. } \\
\text { espécies }\end{array}$ & $\begin{array}{c}\text { N. } \\
\text { famílias }\end{array}$ & $\begin{array}{c}\text { Densidade } \\
\text { (indivíduos.ha- }^{-1} \text { ) }\end{array}$ & $\begin{array}{c}\text { Área basal } \\
\left(\mathbf{m}^{2} \cdot \mathbf{h a}^{-1}\right)\end{array}$ & $\begin{array}{l}\text { N. indivíduos } \\
\text { perfilhados }\end{array}$ & $\begin{array}{l}\text { N. indivíduos } \\
\text { mortos em pé }\end{array}$ \\
\hline Mata do Palmital & 79 & 39 & 1.327 & 38,55 & 35 & 69 \\
\hline Mata do Polonês & 67 & 33 & 1.557 & 46,23 & 138 & 51 \\
\hline Reserva das Antas & 71 & 37 & 1.553 & 33,28 & 32 & 35 \\
\hline
\end{tabular}

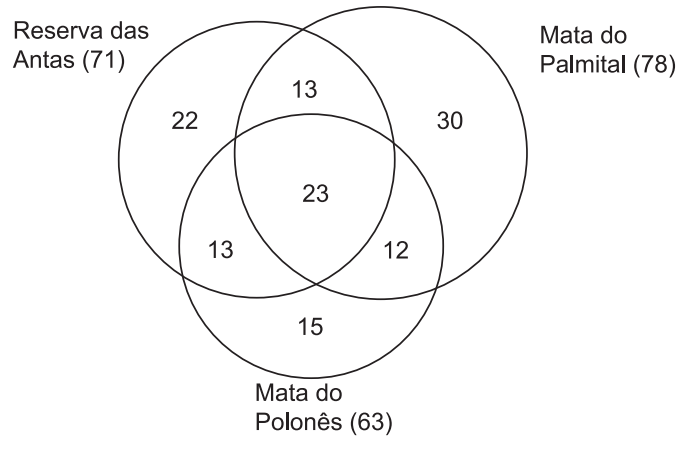

Figura 4. Diagrama de Venn para as três áreas estudadas em Quedas do Iguaçu-PR, demonstrando o número de espécies exclusivas em cada área e comuns a duas ou três áreas. O número entre parênteses após o nome da área representa o número total de espécies.

Figure 4. Venn diagram with the three areas studied in Quedas do Iguaçu-PR, showing number of exclusive species in each area and total shared species for two or three areas. The number within parentheses is the number of species found in each area.

apesar de aparentemente serem mais ricos que alguns fragmentos de FOM de outras regiões do país (e.g. Negrelle \& Silva 1992, Silva et al. 1997, Nascimento et al. 2001), apresentam riqueza inferior a de FES de outras localidades (e.g. Ivanauskas et al. 2002, Rodrigues et al. 2003), bem como a de vários fragmentos de FES, FOM e áreas ecotonais do Paraná (e.g. Galvão et al. 1989, Soares-Silva \& Barroso 1992, Nakajima et al. 1996). A baixa diversidade alfa das florestas estudadas é, no entanto, compensada, em parte, pela diversidade beta na paisagem local, consequência da localização da Fazenda Rio das Cobras numa região de transição, onde espécies da FES e da FOM se substituem, em função de modificações na altitude e, consequentemente, no clima do local. Ainda assim, o número total de espécies amostradas nas três áreas (128) também não é elevado, se comparado ao elevado número de espécies com ocorrência em FES, FOM e áreas de transição no estado do Paraná (ver Dias et al. 2002). Embora seja difícil estabelecer uma relação de causa e efeito para este resultado com base nas informações coletadas nesse estudo, fatores como a intensidade amostral, o critério de inclusão dos indivíduos e o já citado histórico relativamente recente de corte seletivo de espécies madeireiras da região parecem influenciar o número de espécies amostradas.

\section{Caracterização fitogeográfica}

A compilação dos estudos realizados em áreas de FES e FOM na região sul do Brasil e nos estados de São Paulo e Mato Grosso do Sul relacionou 574 espécies arbustivo-arbóreas, sendo 474 na FES e 266 na FOM. Do total de espécies, 163 foram encontradas em ambas as formações, 311 apenas na FES e 103 somente na FOM. Entretanto, quando somente as espécies encontradas em pelo menos cinco levantamentos em cada formação foram consideradas nessa análise, a FES apresentou 82 espécies típicas (encontradas na FES e ausentes na FOM) e a FOM apenas 21 espécies típicas (encontradas na FOM e ausentes na FES), sendo que 26 espécies foram comuns e típicas às duas áreas (Tabela 4).

Nas três áreas estudadas na Fazenda Rio das Cobras foram encontradas tanto espécies típicas da FES quanto espécies típicas da FOM, o que confirma o caráter ecotonal dessa região. Com base nos critérios estabelecidos neste trabalho, na Mata do Polonês foram encontradas quatro espécies classificadas como típicas da FES e duas da FOM, na Reserva das Antas foram amostradas 12 espécies típicas da FES e duas da FOM e na Mata do Palmital 21 espécies típicas da FES e apenas uma da FOM (Tabela 2).

As áreas estudadas apresentam variação no grau de influência da FES e da FOM na composição de espécies. Na Mata do Palmital, por exemplo, a influência da FES é significativamente maior do a influência da FOM na composição florística (teste exato de Fisher, $\mathrm{p}=0,062$ ). Além da ausência de Araucaria angustifolia, principal espécie característica da FOM (Veloso 1992), as espécies com destaque na Mata do Palmital são, com base nos critérios estabelecidos neste estudo, exclusivas à FES, tais como Euterpe edulis, que faz jus ao nome dado ao local e apresenta os maiores valores de densidade relativa. Além disso, compondo o sub-bosque florestal dessa área, em meio aos indivíduos regenerantes de Euterpe edulis, ocorrem Urera baccifera e Sorocea bonplandii, essa última, a espécie de maior índice de valor de importância na FES da bacia do baixo rio Tibagi, estado do Paraná (Dias et al. 2002). No dossel ocorrem ainda indivíduos com mais de $25 \mathrm{~m}$ de altura de Chrysophyllum gonocarpum, Apuleia leiocarpa, Bastardiopsis densiflora, Aspidosperma polyneuron e Balfourodendron riedelianum entre outros, sendo essas duas últimas, espécies tidas como típicas da FES (Veloso 1992, Dias et al. 2002, Torezan 2002).

Para a Reserva das Antas e a Mata do Polonês, no entanto, as proporções de espécies típicas da FES e da FOM não diferem da encontrada nos estudos secundários compilados (teste exato de Fisher, $p=0,372$ e $p=0,451$ respectivamente) e indicam influências não distintas de FES e FOM na composição florística dessas áreas. Na Mata do Polonês destacam-se no sub-bosque florestal Trichilia elegans, Sebastiania brasiliensis e Actinostemon concolor, dentre outras. Já no dossel, ocorrem árvores de até $25 \mathrm{~m}$, principalmente de Nectandra megapotamica, Matayba elaeagnoides, Diatenopteryx sorbifolia e Cordia americana. Estas espécies, citadas tanto para o dossel quanto para o sub-bosque, parecem estar bem representadas tanto na FOM quanto na FES (Silva et al. 1997, Rodrigues 1999, Torezan 2002). Além disso, Sebastiania brasiliensis e as três primeiras espécies citadas para o dossel são comuns à FES e à FOM (Tabela 4).

Na Reserva das Antas, predomina no sub-bosque a pteridófita arborescente Alsophila setosa, que comumente forma grupamentos densos no estrato inferior da FOM (Britez et al. 1995), principalmente 
Tabela 4. Espécies encontradas na FES e ausentes na FOM e vice-versa, amostradas em pelo menos cinco áreas (19,2\% dos trabalhos de cada formação) e espécies comuns a ambas as formações, amostradas em pelo menos 10 das áreas avaliadas (19,2\% do total), sendo no mínimo cinco em cada formação vegetacional. Freq.: frequência com que a espécie foi encontrada em cada formação, no conjunto de levantamentos compilados.

Table 4. Species found on FES, absent on FOM and vice-versa, that were surveyed in five or more areas (19,2\% of surveys in each formation) and species with occurrence in both formations, surveyed in 10 or more areas $(19,2 \%$ of total), with a minimum of five areas in each vegetation type. Freq: Frequency of the species in each vegetation type, considering the group of studies compiled.

\begin{tabular}{|c|c|c|c|c|}
\hline Espécie & Família & Freq. FES & Freq. FOM & Freq. FES + FOM \\
\hline Chrysophyllum gonocarpum (Mart. \& Eichler) Engl. & Sapotaceae & 80,77 & 0 & 40,39 \\
\hline Croton floribundus Spreng. & Euphorbiaceae & 76,92 & 0 & 38,46 \\
\hline Holocalyx balansae Micheli & Fabaceae & 69,23 & 0 & 34,62 \\
\hline Astronium graveolens Jacq. & Anacardiaceae & 65,38 & 0 & 32,69 \\
\hline Trichilia catigua A.Juss. & Meliaceae & 65,38 & 0 & 32,69 \\
\hline Aspidosperma polyneuron Müll.Arg. & Apocynaceae & 61,54 & 0 & 30,77 \\
\hline Jacaratia spinosa (Aubl.) A.DC. & Caricaceae & 57,69 & 0 & 28,85 \\
\hline Balfourodendron riedelianum (Engl.) Engl. & Rutaceae & 53,85 & 0 & 26,93 \\
\hline Copaifera langsdorffii Desf. & Fabaceae & 50,00 & 0 & 25,00 \\
\hline Cariniana estrellensis (Raddi) Kuntze & Lecythidaceae & 50,00 & 0 & 25,00 \\
\hline Casearia gosypiosperma Briq. & Salicaceae & 50,00 & 0 & 25,00 \\
\hline Annona cacans Warm. & Annonaceae & 46,15 & 0 & 23,08 \\
\hline Endlicheria paniculata (Spreng.) J.F. Macbr. & Lauraceae & 46,15 & 0 & 23,08 \\
\hline Trichilia pallida $\mathrm{Sw}$. & Meliaceae & 46,15 & 0 & 23,08 \\
\hline Peltophorum dubium (Spreng.) Taub. & Fabaceae & 42,31 & 0 & 21,16 \\
\hline Trichilia claussenii C. DC. & Meliaceae & 42,31 & 0 & 21,16 \\
\hline Maclura tinctoria (L.) D. Don ex Steud. & Moraceae & 42,31 & 0 & 21,16 \\
\hline Metrodorea nigra A.St.-Hil. & Rutaceae & 42,31 & 0 & 21,16 \\
\hline Tabernaemontana catharinensis A.DC. & Apocynaceae & 38,46 & 0 & 19,23 \\
\hline Alchornea glandulosa Poepp. & Euphorbiaceae & 38,46 & 0 & 19,23 \\
\hline Machaerium nyctitans (Vell.) Benth. & Fabaceae & 38,46 & 0 & 19,23 \\
\hline Guapira opposita (Vell.) Reitz & Nyctaginaceae & 38,46 & 0 & 19,23 \\
\hline Pisonia ambigua Heimerl & Nyctaginaceae & 38,46 & 0 & 19,23 \\
\hline Colubrina glandulosa Perkins & Rhamnaceae & 38,46 & 0 & 19,23 \\
\hline Annona sylvatica A.St.-Hil. & Annonaceae & 34,62 & 0 & 17,31 \\
\hline Cordia ecalyculata Vell. & Boraginaceae & 34,62 & 0 & 17,31 \\
\hline Centrolobium tomentosum Guillemin ex Benth. & Fabaceae & 34,62 & 0 & 17,31 \\
\hline Myrocarpus frondosus Allemão & Fabaceae & 34,62 & 0 & 17,31 \\
\hline Piptadenia gonoacantha (Mart.) J.F. Macbr. & Fabaceae & 34,62 & 0 & 17,31 \\
\hline Ficus guaranitica Chodat. & Moraceae & 34,62 & 0 & 17,31 \\
\hline Esenbeckia febrifuga (A.St.-Hil.) A. Juss. ex Mart. & Rutaceae & 34,62 & 0 & 17,31 \\
\hline Chrysophyllum marginatum (Hook. \& Arn.) Radlk. & Sapotaceae & 34,62 & 0 & 17,31 \\
\hline Cecropia pachystachya Trécul & Urticaceae & 34,62 & 0 & 17,31 \\
\hline Ceiba speciosa (A.St.-Hil) Ravenna & Malvaceae & 30,77 & 0 & 15,39 \\
\hline Plinia rivularis (Cambess.) Rotman & Myrtaceae & 30,77 & 0 & 15,39 \\
\hline Gallesia integrifolia (Spreng.) Harms & Phytolaccaceae & 30,77 & 0 & 15,39 \\
\hline Prockia crucis P. Browne ex L. & Salicaceae & 30,77 & 0 & 15,39 \\
\hline Urera baccifera (L.) Gaudich. ex Wedd. & Urticaceae & 30,77 & 0 & 15,39 \\
\hline Euterpe edulis Mart. & Arecaceae & 26,92 & 0 & 13,46 \\
\hline Protium heptaphyllum (Aubl.) Marchand & Burseraceae & 26,92 & 0 & 13,46 \\
\hline Apuleia leiocarpa (Vogel) J.F. Macbr. & Fabaceae & 26,92 & 0 & 13,46 \\
\hline Hymenaea courbaril L. & Fabaceae & 26,92 & 0 & 13,46 \\
\hline Nectandra oppositifolia Nees \& Mart. & Lauraceae & 26,92 & 0 & 13,46 \\
\hline Ocotea elegans $\mathrm{Mez}$ & Lauraceae & 26,92 & 0 & 13,46 \\
\hline Guarea guidonia (L.) Sleumer & Meliaceae & 26,92 & 0 & 13,46 \\
\hline Guarea kunthiana A. Juss. & Meliaceae & 26,92 & 0 & 13,46 \\
\hline Guarea macrophylla Vahl & Meliaceae & 26,92 & 0 & 13,46 \\
\hline
\end{tabular}


Caracterização de remanescentes florestais do Sudoeste do Paraná

Tabela 4. Continuação...

\begin{tabular}{|c|c|c|c|c|}
\hline Espécie & Família & Freq. FES & Freq. FOM & Freq. FES + FOM \\
\hline Bougainvillea spectabilis Willd. & Nyctaginaceae & 26,92 & 0 & 13,46 \\
\hline Alseis floribunda Schott & Rubiaceae & 26,92 & 0 & 13,46 \\
\hline Coutarea hexandra (Jacq.) K.Schum. & Rubiaceae & 26,92 & 0 & 13,46 \\
\hline Zanthoxylum caribaeum Lam. & Rutaceae & 26,92 & 0 & 13,46 \\
\hline Solanum argenteum Dunal & Solanaceae & 26,92 & 0 & 13,46 \\
\hline Duguetia lanceolata A.St.-Hil. & Annonaceae & 23,08 & 0 & 11,54 \\
\hline Actinostemon klotzschii (Didr.) Pax & Euphorbiaceae & 23,08 & 0 & 11,54 \\
\hline Cassia ferruginea (Schrad.) DC. & Fabaceae & 23,08 & 0 & 11,54 \\
\hline Machaerium villosum Vogel & Fabaceae & 23,08 & 0 & 11,54 \\
\hline Myroxylon peruiferum L. f. & Fabaceae & 23,08 & 0 & 11,54 \\
\hline Trichilia casarettii C.DC. & Meliaceae & 23,08 & 0 & 11,54 \\
\hline Ficus insipida Willd. & Moraceae & 23,08 & 0 & 11,54 \\
\hline Campomanesia guaviroba (DC.) Kiaersk. & Myrtaceae & 23,08 & 0 & 11,54 \\
\hline Savia dictyocarpa Müll.Arg. & Phyllanthaceae & 23,08 & 0 & 11,54 \\
\hline Picramnia ramiflora Engl. & Picramniaceae & 23,08 & 0 & 11,54 \\
\hline Piper amalago $\mathrm{L}$. & Piperaceae & 23,08 & 0 & 11,54 \\
\hline Esenbeckia grandiflora Mart. & Rutaceae & 23,08 & 0 & 11,54 \\
\hline Qualea jundiahy Warm. & Vochysiaceae & 23,08 & 0 & 11,54 \\
\hline Vochysia tucanorum Mart. & Vochysiaceae & 23,08 & 0 & 11,54 \\
\hline Tapirira guianensis Aubl. & Anacardiaceae & 19,23 & 0 & 9,62 \\
\hline Aspidosperma cylindrocarpon Müll.Arg. & Apocynaceae & 19,23 & 0 & 9,62 \\
\hline Zeyeria tuberculosa (Vell.) Bureau & Bignoniaceae & 19,23 & 0 & 9,62 \\
\hline Pachystroma longifolium (Nees) I.M.Johnst. & Euphorbiaceae & 19,23 & 0 & 9,62 \\
\hline Pera glabrata (Schott) Poepp. ex Baill. & Euphorbiaceae & 19,23 & 0 & 9,62 \\
\hline Tetrorchidium rubrivenium Poepp. & Euphorbiaceae & 19,23 & 0 & 9,62 \\
\hline Enterolobium contortisiliquum (Vell.) Morong & Fabaceae & 19,23 & 0 & 9,62 \\
\hline Ocotea silvestris Vattimo & Lauraceae & 19,23 & 0 & 9,62 \\
\hline Mollinedia widgrenii A.DC. & Monnimiaceae & 19,23 & 0 & 9,62 \\
\hline Eugenia blastantha (O. Berg) D. Legrand & Myrtaceae & 19,23 & 0 & 9,62 \\
\hline Eugenia moraviana O.Berg & Myrtaceae & 19,23 & 0 & 9,62 \\
\hline Eugenia ramboi D.Legrand & Myrtaceae & 19,23 & 0 & 9,62 \\
\hline Rhamnidium elaeocarpum Reissek & Rhamnaceae & 19,23 & 0 & 9,62 \\
\hline Ixora venulosa Benth. & Rubiaceae & 19,23 & 0 & 9,62 \\
\hline Zanthoxylum riedelianum Engl. & Rutaceae & 19,23 & 0 & 9,62 \\
\hline Aloysia virgata (Ruiz \& Pav.) Juss & Verbenaceae & 19,23 & 0 & 9,62 \\
\hline Araucaria angustifolia (Bertol.) Kuntze & Araucariaceae & 0 & 80,77 & 40,38 \\
\hline Capsicodendron dinisii (Schwacke) Occhioni & Canellaceae & 0 & 50,00 & 25,00 \\
\hline Drimys brasiliensis Miers & Winteraceae & 0 & 38,46 & 19,23 \\
\hline Annona emarginata (Schltdl.) H.Rainer & Annonaceae & 0 & 34,62 & 17,31 \\
\hline Lamanonia speciosa (Cambess.) L.B. Sm. & Cunoniaceae & 0 & 34,62 & 17,31 \\
\hline Myrcia hatschbachii D.Legrand & Myrtaceae & 0 & 30,77 & 15,39 \\
\hline Podocarpus lambertii Klotzsch ex Endl. & Podocarpaceae & 0 & 30,77 & 15,39 \\
\hline Piptocarpha angustifolia Dusén ex Malme & Asteraceae & 0 & 26,92 & 13,46 \\
\hline Dicksonia sellowiana (Hook.) Maxon & Dicksoniaceae & 0 & 26,92 & 13,46 \\
\hline Sloanea lasiocoma K.Schum & Elaeocarpaceae & 0 & 26,92 & 13,46 \\
\hline Cinnamomum vesiculosum (Nees) Kosterm. & Lauraceae & 0 & 26,92 & 13,46 \\
\hline Zanthoxylum kleinii (R.S.Cowan) P.G.Waterman & Rutaceae & 0 & 26,92 & 13,46 \\
\hline Duranta vestita Cham. & Verbenaceae & 0 & 26,92 & 13,46 \\
\hline Erythroxylum deciduum A.St.-Hil. & Erythroxylaceae & 0 & 23,08 & 11,54 \\
\hline Eugenia uruguayensis Cambess. & Myrtaceae & 0 & 23,08 & 11,54 \\
\hline Picramnia parvifolia Engl. & Picramniaceae & 0 & 23,08 & 11,54 \\
\hline
\end{tabular}


Tabela 4. Continuação...

\begin{tabular}{|c|c|c|c|c|}
\hline Espécie & Família & Freq. FES & Freq. FOM & Freq. FES + FOM \\
\hline Scutia buxifolia Reissek & Rhamnaceae & 0 & 23,08 & 11,54 \\
\hline Ilex microdonta Reissek & Aquifoliaceae & 0 & 19,23 & 9,62 \\
\hline Mimosa scabrella Benth. & Fabaceae & 0 & 19,23 & 9,62 \\
\hline Guettarda uruguensis Cham. \& Schltdl. & Rubiaceae & 0 & 19,23 & 9,62 \\
\hline Siphoneugenia reitzii D.Legrand & Myrtaceae & 0 & 19,23 & 9,62 \\
\hline Campomanesia xanthocarpa (Mart.) O.Berg & Myrtaceae & 61,54 & 80,77 & 71,15 \\
\hline Prunus myrtifolia (L.) Urb. & Rosaceae & 50,00 & 88,46 & 69,23 \\
\hline Casearia decandra Jacq. & Salicaceae & 50,00 & 84,62 & 67,31 \\
\hline Cedrela fissilis Vell. & Meliaceae & 65,38 & 57,69 & 61,54 \\
\hline Casearia sylvestris $\mathrm{Sw}$. & Salicaceae & 73,08 & 46,15 & 59,62 \\
\hline Matayba elaeagnoides Radlk. & Sapindaceae & 42,31 & 73,08 & 57,69 \\
\hline Nectandra megapotamica (Spreng.) Mez & Lauraceae & 53,85 & 61,54 & 57,69 \\
\hline Syagrus romanzoffiana (Cham.) Glassman & Arecaceae & 69,23 & 42,31 & 55,77 \\
\hline Allophylus edulis (A. St.-Hil., Cambess. \& A. Juss.) Radlk. & Sapindaceae & 38,46 & 69,23 & 53,85 \\
\hline Cupania vernalis Cambess. & Sapindaceae & 42,31 & 65,38 & 53,85 \\
\hline Myrsine umbellata Mart. & Myrsinaceae & 42,31 & 57,69 & 50,00 \\
\hline Machaerium stipitatum (DC.) Vogel & Fabaceae & 69,23 & 23,08 & 46,15 \\
\hline Ocotea puberula (Rich.) Nees & Lauraceae & 23,08 & 69,23 & 46,15 \\
\hline Cabralea canjerana (Vell.) Mart. & Meliaceae & 61,54 & 23,08 & 42,31 \\
\hline Luehea divaricata Mart. & Malvaceae & 30,77 & 50,00 & 40,38 \\
\hline Myrcia splendens (Sw.) DC. & Myrtaceae & 42,31 & 38,46 & 40,38 \\
\hline Roupala brasiliensis Klotzsch & Proteaceae & 38,46 & 42,31 & 40,38 \\
\hline Sebastiania commersoniana (Baill.) L.B. \& Downs & Euphorbiaceae & 19,23 & 61,54 & 40,38 \\
\hline Sebastiania brasiliensis Spreng. & Euphorbiaceae & 34,62 & 38,46 & 36,54 \\
\hline Zanthoxylum rhoifolium Lam. & Rutaceae & 19,23 & 53,85 & 36,54 \\
\hline Sapium glandulosum (L.) Morong & Euphorbiaceae & 19,23 & 50,00 & 34,62 \\
\hline Eugenia uniflora $\mathrm{L}$. & Myrtaceae & 23,08 & 42,31 & 32,69 \\
\hline Casearia obliqua Spreng. & Salicaceae & 19,23 & 34,62 & 26,92 \\
\hline Eugenia involucrata DC. & Myrtaceae & 19,23 & 34,62 & 26,92 \\
\hline Aegiphila sellowiana Cham. & Lamiaceae & 19,23 & 19,23 & 19,23 \\
\hline Allophylus guaraniticus (St. Hil.) Radlk. & Sapindaceae & 19,23 & 19,23 & 19,23 \\
\hline
\end{tabular}

nos locais de solo com alta umidade e até mesmo encharcado (obs. pess.). Syagrus romanzoffiana, também encontrada nessa área, porém em menor densidade, parece ser também indicativa de formações ribeirinhas e de várzeas. Ainda no estrato inferior da Reserva das Antas, são encontrados nos locais de melhor drenagem do solo indivíduos de Cordyline spectabilis e Casearia sylvestris. No dossel, raramente as árvores atingem $25 \mathrm{~m}$, predominando Nectandra megapotamica, Cordia americana, Ocotea diospyrifolia e Prunus myrtifolia, dentre outras espécies. As espécies dominantes do dossel e do estrato inferior da Reserva das Antas ocorrem em ambas as formações, FOM e FES, em outras bacias hidrográficas do estado do Paraná (Dias et al. 2002). Além disso, assim como evidenciado para a Mata do Polonês, muitas destas espécies são consideradas comuns a FES e a FOM (Tabela 3).

Tanto na Reserva das Antas quanto na Mata do Polonês foram amostrados indivíduos de Araucaria angustifolia, espécie endêmica (ver Stehmann et al. 2009) e principal característica da FOM (Veloso 1992, Tabela 4). Este resultado evidencia a maior influência da FOM na composição florística dessas áreas do que na área da Mata do Palmital. Entretanto, apesar da relativa proximidade de Quedas do Iguaçu com a região central (core) da FOM (FUPEP 2001), Araucaria angustifolia não ocupou uma posição de destaque em relação à abundância em nenhuma destas áreas. Este aspecto é resultante não só do fato das áreas estarem numa região de transição, onde existem ecótonos com elementos de FES e FOM na composição, mas também da intensiva extração madeireira nas florestas da região. Segundo relato dos próprios moradores locais, até poucas décadas atrás, as florestas da Fazenda Rio das Cobras eram, com exceção das áreas mais próximas ao rio Iguaçu (e.g. Mata do Palmital), "pretas" de Araucaria angustifolia (referência ao verde escuro, quase preto, peculiar das folhas do pinheiro-do-paraná). Além de Araucaria angustifolia, foram exploradas outras espécies madeireiras, tais como Cedrela fissilis, Cordia trichotoma e Peltophorum dubium, na proporção de dois entre cada três indivíduos da população (Consórcio Silviconsult-Juris Ambientis 1995), fato responsável pela baixa densidade de muitas espécies madeireiras nas áreas estudadas.

De uma forma geral, os resultados da avaliação da estrutura, composição florística e riqueza das florestas estudadas indicam que a vegetação nativa remanescente da Fazenda Rio das Cobras corresponde a florestas secundárias, que passaram por eventos de perturbação antropogênica influenciadores de seu estágio de conservação atual. Entretanto, excetuando-se o Parque Nacional do Iguaçu, localizado a cerca de $100 \mathrm{~km}$ de distância, não há na paisagem regional situação similar à da Fazenda Rio das Cobras no 
que diz respeito à extensão de área de vegetação nativa remanescente. Este fato, associado à presença de espécies de FES e FOM, duas fitoformações importantes e ameaçadas da Mata Atlântica, e à ocorrência de espécies arbóreas nacional e globalmente ameaçadas de extinção, reforçam o valor da área do ponto de vista ecológico e de conservação da biodiversidade regional.

Além disso, os resultados desse estudo indicam a área como uma área de transição entre a FES e a FOM e parecem corroborar que, na região estudada, a FES e suas espécies típicas se irradiam principalmente pelos vales dos grandes rios (vide Mata do Palmital - vale do Rio Iguaçu), onde a altitude é menor (próxima ou inferior aos $500 \mathrm{~m}$ ) e a temperatura maior, com lenta substituição por espécies da FOM na direção dos planaltos (vide Mata do Polonês e Reserva das Antas), até se chegar à área central da FOM, dominada por Araucaria angustifolia e outras espécies típicas dessa formação (Maack 1981, Fundação de Pesquisas Florestais do Paraná 2001).

\section{Agradecimentos}

Os autores agradecem a Lisandro Inakake e aos membros do Projeto de Assentamento Celso Furtado pela colaboração fundamental nas atividades de campo e a Helena Maria Maltez pelas críticas e sugestões dadas.

\section{Referências Bibliográficas}

ANGIOSPERM PHYLOGENY GROUP - APG. 2009. An update of the Angiosperm Phylogeny Group classification for the orders and families of flowering plants: APG III. Bot. J. Linn. Soc. 161(2):105-121.

ARRUDA, L. \& DANIEL, O. 2007. Florística e diversidade em um fragmento de Floresta Estacional Semidecidual Aluvial em Dourados, MS. Floresta 37:189-199.

BARDDAL, M.L., RODERJAN, C.V., GALVÃO, F., CURCIO, G.R. 2004. Caracterização florística e fitossociológica de um trecho sazonalmente inundável de floresta aluvial, em Araucária, PR. Cienc. Florest. 14(2):37-50.

BERTANI, D.F., RODRIGUES, R.R., BATISTA, J.L.F. \& SHEPHERD, G.J. 2001. Análise temporal da heterogeneidade florística e estrutural em uma floresta ribeirinha. Rev. Bras. Bot. 24:11-23.

BIACHINI, E., POPOLO, R.S., DIAS, M.C. \& PIMENTA, J.A. 2003 Diversidade e estrutura de espécies arbóreas em área alagável do município de Londrina, Sul do Brasil. Acta Bot. Bras. 17:405-419.

BRITEZ, R.M., SILVA, S.M., SOUZA, W.S. \& MOTTA, J.T.W. 1995. Levantamento florístico em Floresta Ombrófila Mista, São Mateus do Sul, Paraná, Brasil. Arq. Biol. Tecnol. 38:1147-1161.

BRUNETTO, R.S., BELOTTI, A., SOBRAL, L.S., GOTTARDI, E. 2003. Estrutura florística e fitossociológica de remanescentes da mata ciliar do lajeado São José - Chapecó (SC). UNOPAR Cient., Ciênc. Biol. Saúde, 5-6(1):69-76.

CAVASSAN, O., CESAR, O. \& MARTINS, F.R. 1984. Fitossociologia da vegetação arbórea da Reserva Estadual de Bauru, Estado de São Paulo. Rev. Bras. Bot. 7:91-106.

CESAR, O. \& LEITÃO-FILHO, H.F. 1990. Estudo fitossociológico de mata mesófila semidecídua na Fazenda Barreiro Rico, Município de Anhembi, SP. Rev. Bras. Bot. 50:443-452.

CHAGAS E SILVA, F., FONSECA, E.P., SOARES-SILVA, L.H., MULLER, C. \& BIANCHINI, E. 1995. Composição florística e fitossociologia do componente arbóreo das florestas ciliares da bacia do rio Tibagi. 3. Fazenda Bom Sucesso, município de Sapopema, PR. Acta Bot. Bras. 9(2):289-302.

CONSERVATION INTERNATIONAL DO BRASIL, FUNDAÇÃO SOS MATA ATLÂNTICA, FUNDAÇÃO BIODIVERSITAS, INSTITUTO DE PESQUISAS ECOLÓGICAS, SECRETARIA DO MEIO AMBIENTE DO ESTADO DE SÃO PAULO \& SEMAD/INSTITUTO ESTADUAL DE FLORESTAS-MG. 2000. Avaliação e ações prioritárias para a conservação da biodiversidade da Mata Atlântica e Campos Sulinos. MMA/SBF, Brasília.

CONSÓRCIO SILVICONSULT - JURIS AMBIENTIS. 1995. Estudo de impacto ambiental: projeto agroflorestal Fazenda Rio das Cobras. Curitiba.
CORDEIRO, J. \& RODRIGUES, W.A. 2007. Caracterização fitossociológica de um remanescente de floresta ombrófila mista em Guarapuava, PR. R. Árvore 31:(3):545-554.

COSTA-FILHO, L.V., NANNI, M.R. \& CAMPOS, J.B. 2006. Floristic and Phytosociological Description of a Riparian Forest and the Relationship with the Edaphic Environment in Caiuá Ecological Station - Paraná Brazil. Braz. Arch. Biol. Technol. 49(5):785-798.

DI BITETTI, M.S., PLACCI, G. \& DIETZ, L.A. 2003. Uma visão de biodiversidade para a ecorregião Florestas do Alto Paraná - bioma Mata Atlântica: planejando a paisagem de conservação da biodiversidade e estabelecendo prioridades para ações de conservação. World Wildlife Fund, Washington.

DIAS, M.C., VIEIRA, A.O.S. \& PAIVA, M.R.C. 2002. Florística e fitossociologia das espécies arbóreas das florestas da bacia do rio Tibagi. In A bacia do rio Tibagi (M.E. Medri, E. Bianchini, O.A. Shibatta \& J.A. Pimenta, ed.). Londrina, p.109-124.

DIAS, M.C., VIEIRA, A.O.S., NAKAJIMA, J.N., PIMENTA, J.A. \& LOBO, P.C. 1998. Composição florística e fitossociologia do componente arbóreo das florestas ciliares do rio Iapó, na bacia do rio Tibagi, Tibagi, PR. Rev. Bras. Bot. 21(2):183-195.

DICKINSON, M.B., WHINGHAM, D.F. \& HERMANN, S.M. 2000. Tree regeneration in felling and natural treefall disturbance in a Semideciduous Tropical Forest in Mexico. For. Ecol. Manage. 134:137-151.

DINERSTEIN, E., OLSON, D.M., GRAHAM, D., WEBSTER, A., PRIMM, S., BOOKBINDER, M. \& LEDEC, G. 1995. A conservation assessment of the terrestrial ecoregions of Latin America and the Caribbean. The World Bank in association with The World Wildlife Fund, Washington.

DURIGAN, G., SANTOS, J.D. \& GANDARA, F.B. 2002. Fitossociologia de dois fragmentos de Floresta Estacional Semidecidual no Pontal do Paranapanema. Rev. Inst. Florest. 14(1):13-26.

FORMENTO, S., SCHORN, L.A. \& RAMOS, R.A.B. 2004. Dinâmica estrutural arbórea de uma floresta ombrófila mista em Campo Belo do Sul, SC. Cerne 10(2):196-212.

FUNDAÇÃO DE PESQUISAS FLORESTAIS DO PARANÁ - FUPEF. 2001. Conservação do Bioma Floresta com Araucária: diagnóstico dos remanescentes florestais. Fundação de Pesquisas Florestais do Paraná, Curitiba, v.1.

FUNDAÇÃO SOS MATA ATLÂNTICA \& INSTITUTO NACIONAL DE PESQUISAS ESPACIAIS - INPE. 2009. Atlas dos remanescentes florestais e ecossistemas associados do domínio da mata atlântica no período 2005-2008. São Paulo.

GALVÃO, F., KUNIYOSHI, Y.S. \& RODERJAN, C.V. 1989. Levantamento fitossociológico das principais associações arbóreas da Floresta Nacional de Irati. Revista Floresta 19(1-2):30-49.

GERALDI, S.E., KOEHLER, A.B. \& KAUANO, E.E. 2005. Levantamento fitossociológico de dois fragmentos da floresta Ombrófila Mista, em Tijucas do Sul, Paraná. Rev. Acadêmica 3(2):27-36.

INTERNATIONAL UNION FOR CONSERVATION OF NATURE - IUCN 2009. IUCN Red List of Threatened Species. Version 2009.2. Disponível em http://www.iucnredlist.org (último acesso em 10/01/2010).

IVANAUSKAS, N.M., NAVE, A.G. \& RODRIGUES, R.R. 2002 Fitossociologia de um remanescente de Floresta Estacional Semidecidual em Itatinga-SP, para fins de restauração de áreas degradadas. Rev. Arvore 26(1):43-57.

JARENKOW, J.A. \& WAECHTER, J.L. 2001. Composição, estrutura e relações florísticas do componente arbóreo de uma floresta estacional no Rio Grande do Sul, Brasil. Revta Brasil. Bot. 24:263-272.

JURINITZ, C.F \& JARENKOW, J.A. 2003. Estrutura do componente arbóreo de uma floresta estacional na Serra do Sudeste, Rio Grande do Sul, Brasil. Revta Brasil. Bot. 26:475-487.

KAMMESHEIDT, L. 1998. The role of tree sprouts in the restoration of structure and species diversity in tropical moist forest after slash-and-burn agriculture in Eastern Paraguay. Plant Ecol. 139:155-165.

KOZERA, C., DITTRICH, V.A.O. \& SILVA, S.M. 2006. Fitossociologia do componente arbóreo de um fragmento de floresta ombrófila mista montana, Curitiba, PR, BR. Floresta 36(2):225-237.

LONGHI, S.J., BRENA, D.A., GOMES, J.F., NARVAES, I.S., BERGER, G. \& SALIGO, A.J. Classificação e caracterização de Estágios sucessionais em remanescentes de Floresta Ombrófila Mista na FLONA de São Francisco de Paula, RS, Brasil. Cienc. Florest.16(2):113-125.

MAACK, R. 1981. Geografia física do Estado do Paraná. 2 ed. José Olympio, Rio de Janeiro. 
MARTINS, F.R. 1991. Estrutura de uma floresta mesófila. Editora da UNICAMP, Campinas.

MISSOURI BOTANICAL GARDEN - MOBOT. Disponível em: http://www. tropicos.org/ (último acesso em 27/12/2008).

MYERS, N., MITTERMEIER, R.A., MITTERMEIER, C.G., FONSECA, G.A.B. \& KENT, J. 2000. Biodiversity hotspots for conservation priorities. Nature 403:853-858.

NAKAJIMA, J.M., SOARES-SILVA, L.H., MEDRI, M.E., GOLDENBERG, R. \& CORREA, G.T. 1996. Composição florística e fitossociológica do componente arbóreo das florestas ripárias da bacia do Rio Tibagi: 5. Fazenda Monte Alegre, município de Telêmaco Borba, Paraná. Arq. Biol. Tecnol. 39(4):933-948.

NASCIMENTO, A.R.T., LONGHI, L.S. \& BRENA D.A. 2001. Estrutura e padrões de distribuição espacial de espécies arbóreas em uma amostra de Floresta Ombrófila Mista em Nova Prata, RS. Cienc. Florest. 11(1):105-119.

NASCIMENTO, H.E.M., DIAS, A.S. TABANEZ, A.A. J. \& VIANA, V.M. 2007. Estrutura e dinâmica de populações arbóreas de um fragmento de floresta estacional semidecidual na região de Piracicaba, SP. Rev. Brasil. Biol. 59(2):329-342.

NEGRELLE, R.A.B. \& SILVA, F.C. 1992. Fitossociologia de um trecho de Floresta com Araucaria Angustifolia (Bert.) O. Ktze. no município de Caçador-SC. Bol. Pesqui. Florest. 24:37-54.

NEGRELLE, R.R.B. \& LEUCHTENBERGER, R. 2001. Composição e estrutura do componente arbóreo de um remanescente de floresta ombrófila mista. Rev. Florest. 31(1-2):42-51.

OLIVEIRA FILHO, A.T. 2006. Catálogo das árvores nativas de Minas Gerais: mapeamento e inventário da flora nativa e dos reflorestamentos de Minas Gerais. Editora UFLA, Lavras.

OLIVEIRA, Y.M.M. \& ROTTA, E. 1982. Levantamento da estrutura horizontal de uma Mata de araucária do primeiro planalto paranaense. Bol. Pesqui. Florest. 4:1-46.

RIBEIRO, M.C., METZGER, J.P., MARTENSEN, A.C., PONZONI, F.J. \& HIROTA, M.M. 2004. The Brazilian Atlantic Forest: how much is left, and how is tge remaining forests distributed? Implications for conservation. Biol. Conserv. 142:1141-1153.

RODRIGUES, L.A., CARVALHO, D.A., OLIVEIRA FILHO, A.R., BOTREL, R.T. \& SILVA, E.A. 2003. Florística e estrutura da comunidade arbórea de um fragmento florestal em Luminárias, MG. Acta Bot. Bras. 17(1):71-87.

RODRIGUES, R.R. 1999. A vegetação de Piracicaba e municípios do entorno. Circular técnica IPEF 189:1-17.

RODRIGUES, R.R., MORELLATO, L.P.C., JOLY, C.A. \& LEITÃO FILHO, H.F. 1989. Estudo florístico e fitossociológico em um gradiente altitudinal de mata mesófila semidecídua na Serra do Japi, Jundiaí, SP. Rev. Bras. Bot. 12(1):71-84.

RODRIGUES, R.R., TORRES, R.B., MATTHES, L.A.F. \& PENHA, A.S. 2004. Tree species sprouting from root buds in a Semideciduous Forest affected by fires. Braz. Arch. Biol. Technol. 47(1):127-133.

RONDON-NETO, R.M., KOZERA, C., ANDRADE, R.R., CECY, A.T., HUMMES, A.P., FRITZSSONS, E., CALDEIRA, M.V.W., MACIEL, M.N.M. \& SOUZA, M.K.F. 2002. Caracterização florística e estrutural de um fragmento de floresta ombrófila mista em Curitiba, PR - Brasil. Revista Floresta 32(1):3-16.

SALIS, S.M., TAMASHIRO, J.Y. \& JOLY, C.A. 1994. Florística e fitossociologia do estrato arbóreo de um remanescente de mata ciliar do rio Jacaré-Pepira, Brotas, SP. Rev. Bras. Bot. 119:155-164.

SCHAAF, L.B., FIGUEIREDO FILHO, A., GALVÃO, F., SANQUETTA, C.R. \& LONGHI, S.J. Modificações florístico-estruturais de um remanescente de Floresta Ombrófila Mista Montana no período entre 1979 e 2000. Cienc. Florest. 16(3):271-291.

SEGER, C., DLUGOSZ, F., KURASZ, G., MARTINEZ, D., RONCONI, E., MELO, L., BITTENCOURT, S., BRAND, M., CARNIATTO, I., GALVÃO, F., RODERJAN, C. Levantamento florístico e análise fitossociológico de um remanescente de Floresta Ombrófila Mista localizado no Município de Pinhais, Paraná - Brasil. Floresta 35(2):291-302.
SILVA, J.A., SALOMÃO, A.N., GRIPP, A. \& LEITE, E.J. 1997. Phytosociological survey in Brazilian forest genetic reserve of Caçador. Plant Ecol. 133:1-11.

SILVA, L.A. \& SOARES, J.J. 2002. Levantamento fitossociológico em um fragmento de floresta estacional semidecídua, no município de são carlos, SP. Acta Bot. Bras. 16(2):205-216.

SILVA, S.M., SILVA, F.C., VIEIRA, A.O.S., NAKAJIMA, J.N., PIMENTA, J.A. \& COLLI, S. 1992. Composição florística e fitossociologia do componente arbóreo das florestas ciliares da bacia do rio Tibagi, Paraná: 2. Várzea do rio Bitumirim, município de Ipiranga, PR. In $2^{\circ}$ Congresso Nacional Sobre Essências Nativas. Instituto Florestal, São Paulo, p.192-198.

SMITH, A.R., PRYER, K.M., SCHUETTPELZ, E., KORALl, P., SCHNEIDER, H. \& WOLF, P.G. 2006. A classification for extant ferns. Taxon 55:705-731.

SOARES-SILVA, L.H, BIANCHINI, E., FONSECA, E.P., DIAS, M.C., MEDRI, M.C. \& FILHO, W.Z. 1992. Composição florística e fitossociológica do componente arbóreo das florestas ciliares da bacia do rio Tibagi. 1. Fazenda Doralice - Ibiporã, PR. In $2^{\circ}$ Congresso Nacional Sobre Essências Nativas. Instituto Florestal, São Paulo, p.199-205.

SOARES-SILVA, L.H. \& BARROSO, G.M. 1992. Fitossociologia do estrato arbóreo na porção norte do Parque Estadual Mata dos Godoy, Londrina PR, Brasil. In $8^{\circ}$ Congresso da Sociedade Botânica de São Paulo. SBSP, São Paulo, p.101-112.

SOUZA, R.P.M. 2008. Estrutura da comunidade arbórea de trechos de florestas de Araucária no estado de São Paulo, Brasil. Dissertação de Mestrado, Universidade de São Paulo, Escola Superior de Agricultura Luiz de Queiroz, Piracicaba.

SOUZA, V.C. \& LORENZI, H. 2008. Botânica sistemática: guia ilustrado para identificação das famílias de fanerógamas nativas e exóticas no Brasil, baseado em APG II. 2 ed. Instituto Plantarum. Nova Odessa.

STEHMANN, J.R., FORZZA, R.C., SALINO, A., SOBRAL, M., DA COSTA, D.P. \& KAMINO, L.H.Y. 2009. Plantas da Floresta Atlântica. Jardim Botânico do Rio de Janeiro, Rio de Janeiro.

TOLEDO FILHO, D.V., BERTONI, J.E.A., BATISTA, E.A. \& PARENTE, P.R. 2000. Fitossociologia de um fragmento Florestal à margem do Rio do Peixe, Município de Lindóia (SP). Rev. Inst. Florest. 12:37-45.

TOLEDO FILHO, D.V., LEITÃO FILHO, H.F., BERTONI, J.E.A., BATISTA, E.A. \& PARENTE, P.R. 1993. Composição florística do estrato arbóreo da Reserva Estadual de Águas da Prata - (SP). Rev. Inst. Florest. 5:113-122.

TOMÉ, M.V.D.F., MIGLIORANZA, E., VILHENA, A.H.T. \& FONSECA, E.P. 1999. Composição florística e fitossociológica do Parque Estadual Mata São Francisco. Rev. Inst. Florest. 11(1):13-23.

TOREZAN, J.M.D. 2002. Nota sobre a vegetação do rio Tibagi. In A bacia do rio Tibagi (M.E. Medri, E. Bianchini, O.A. Shibatta \& J.A. Pimenta, ed.). Londrina, p.103-108.

VASCONCELLOS, J.M.O., DIAS, L.L., SILVA, C.P. \& SOBRAL, M. 1992. Fitossociologia de uma área de mata subtropical no Parque Estadual do Turvo - RS. Revista do Instituto Florestal 4:252-259.

VEIGA, M.N., MARTINS, S.S., SILVA, I.C., TORMENA, C.A. \& SILVA, O.H. 2003. Avaliação dos aspectos florísticos de uma mata ciliar no Norte do Estado do Paraná. Acta Sci., Agron. 25:519-525.

VELOSO, H.P. 1992. Manual técnico da vegetação brasileira. IBGE Departamento de Recursos Naturais e Estudos Ambientais, Rio de Janeiro.

VIEIRA, M.G.L., MORAES, J.L., BERTONI, J.E.A., MARTINS, F.R. \& ZANDARIN, M.A. 1989. Composição florística e estrutura fitossociológica da vegetação arbórea do Parque Estadual de Vassununga, Santa Rita do Passa Quatro (S.P.) II - Gleba Capetinga Oeste. Rev. Inst. Flor. 1(1):135-159. 